\title{
Impacto dos Fundos Setoriais sobre a Produtividade Acadêmica de Cientistas Universitários
}

\author{
Sérgio Kannebley Júnior \\ Professor - Faculdade de Economia, Administração e Contabilidade (FEA-RP/USP) \\ End. para contato: Av. Bandeirantes, 3900 - Cidade Universitária, Ribeirão Preto \\ São Paulo - Brasil - CEP:14040-900 - E-mail: skj@usp.br

\begin{abstract}
Murilo Damião Carolo (FEA-RP/USP) - End. para contato: Av. Bandeirantes, 3900 - Cid. Universitária, Ribeirão Preto São Paulo - Brasil - CEP: 14040-900 - E-mail: murilocarolo@gmail.com
\end{abstract} \\ Mestre em Economia Aplicada PPGE - Faculdade de Economia, Administração e Contabilidade
}

\section{Fernanda de Negri}

Pesquisadora - Instituto de Pesquisa Econômica e Aplicada (Ipea)

End. para contato: SBS - quadra 1 - Ed. BNDES - $11^{\circ}$ andar - Brasilia, DF - Brasil

CEP: 70076-900 - E-mail: fernanda.denegri@ipea.gov.br

Recebido em 15 de janeiro de 2012. Aceito em 30 de janeiro de 2013.

\section{Resumo}

O artigo tem o objetivo de avaliar o impacto sobre a produtividade científica dos pesquisadores universitários envolvidos em projetos de pesquisa financiados pelos Fundos Setoriais. Foram reunidos dados sobre o desempenho de pesquisadores brasileiros e suas relações com os Fundos Setoriais, para o período de 2000 a 2008, a partir das bases de dados da Plataforma Lattes do CNPq e de financiamento dos Fundos Setoriais, fornecida pelo MCTI. As evidências obtidas demonstram um impacto geral positivo da interação Universidade - Fundos Setoriais sobre a produtividade científica dos pesquisadores pertencentes à amostra. O impacto global da política de financiamento de fundos setoriais deve ter levado a um aumento de $5 \%$ a $6 \%$ na produção acadêmica dos pesquisadores universitários no período considerado. Adicionalmente, a estimação do ciclo de vida dos pesquisadores brasileiros revelou que o pico da produção científica de um pesquisador ocorre em torno dos 57 anos de idade.

\section{Palavras-Chave}

universidade, produtividade científica, modelos com dados em painel

\begin{abstract}
The article aims to assess the impact on the scientific productivity of academic researchers involved in research projects funded by the Sector Funds. We gathered data on the performance of Brazilian researchers, and their relationships with Sector Funds for the period 2000 to 2008, from databases Lattes CNPq and funding base of Sector Funds, provided by MCT. Evidence obtained shows an overall positive impact on the scientific productivity of researchers in the sample. The global impact of financing policy for Sector Funds must have led to an increase of $5 \%$ to $6 \%$ in the studies of academic researchers over the period. Additionally, the estimation of the Brazilian's researchers life cycle found that the peak of scientific output of a researcher presenting at around 57 years old.
\end{abstract}




\section{Keywords}

university, scientific productivity, models with panel data

\section{JEL Classification}

$120,030, \mathrm{C} 23$

\section{Introdução}

A relação entre ciência e tecnologia e a interação entre academia e empresas são temas que vêm recebendo crescente atenção tanto pelos economistas aplicados, como por parte dos formuladores de política econômica. A universidade transita para um modo de produção de conhecimento mais fortemente direcionado pela demanda, em que a interação entre empresa e universidade define novas formas de produção e transferência de conhecimento para o sistema produtivo, bem como alternativas formas de financiamento para a pesquisa acadêmica.

Considerando esse novo quadro, a estrutura de políticas de inovação e os seus componentes institucionais, que dão suporte a essas políticas, foi recentemente aprimorada no Brasil. Como destacam De Negri et al. (2009), o conjunto de instituições, políticas e atores que compõe o sistema brasileiro de inovação é bastante amplo, envolvendo desde universidades, centros de pesquisa, empresas e instituições de regulação, até órgãos federais e estaduais. Entre as principais políticas do sistema brasileiro de inovação ressalta-se a atuação dos Fundos Setoriais (FS), administrado pela Financiadora de Estudos e Projetos (FINEP), também vinculada ao MCTI (Ministério de Ciência, Tecnologia e Inovação) ${ }^{1}$.

Segundo Pacheco (2007) os fundos setoriais foram elaborados na perspectiva de alterar de forma radical o panorama de financiamento do setor de C\&T no Brasil, e de modificar o relacionamento do MCT e de suas Agências de Fomento (CNPq e FINEP) com os demais órgãos setoriais do Governo Federal. Dentro dessa mudança de

1 Há 16 fundos setoriais, sendo 14 relativos a setores específicos e dois transversais. Destes, um é voltado à interação universidade-empresa (Fundo verde-amarelo), enquanto o outro é destinado a apoiar a melhoria da infraestrutura de ICT (tecnologias da informação e comunicação). Os fundos setoriais são: CT-Aero, CT-Agro, CT-Amazônia, CT-Aquaviário, CT-Biotec, CT-Energ, CT-Espacial, CT-Hidro, CT-Info, CT-Infra, CT-Mineral, CT-Petro, CT-Saúde, CT-Transporte, Fundo Verde Amarelo e Funttel. 
perspectiva de alteração radical está a orientação de que os recursos destinados a esses fundos devem ser direcionados para o financiamento de programas de amparo à pesquisa científica e ao desenvolvimento tecnológico do setor produtivo havendo, segundo Pereira (2005), uma "clara orientação para o desenvolvimento de processos e produtos com potencial de competitividade no mercado".

Entretanto, do ponto de vista das universidades, a interação com empresas na realização de projetos de pesquisa não é consensual. Se por um lado, para as universidades é crescente o interesse nessa interação na medida em que o setor privado oferece a oportunidade de nova fonte de recursos e aumento do prestígio institucional e do pesquisador, existem argumentos contrários a essa interação que ressaltam a existência de potenciais "efeitos negativos" da participação de universidades no desenvolvimento de tecnologias voltadas para comercialização. Embora não consensuais, uma das preocupações apontadas por essa forma de interação entre empresa e universidade está relacionada à pauta de pesquisa das universidades e o desvio da pesquisa básica em direção à pesquisa aplicada, introduzindo um viés no sentido de certas áreas e atividades mais aplicadas. Outra possibilidade é o docente dedicar-se mais à realização da pesquisa aplicada do que à condução de suas atividades tradicionais na instituição, incluindo a licenciatura. Caso essa pesquisa aplicada não tenha forte relação com o desenvolvimento científico da área, deve haver uma diminuição da probabilidade de publicação, impactando, consequentemente, sobre a produtividade científica do pesquisador. ${ }^{2}$

Assim, é sob o ponto de vista da produtividade acadêmica que esse artigo se propõe a analisar o caso da interação das Universidades com os Fundos Setoriais. Ou seja, o artigo busca avaliar o impacto sobre a produtividade científica dos pesquisadores universitários envolvidos em projetos financiados pelos fundos setoriais, considerando a possibilidade de existência tanto de efeitos positivos, como negativos dessa interação. Nesse trabalho o conceito de produtividade será considerado apenas do ponto de vista quantitativo, ficando para

2 O caráter não consensual dessas preocupações se deve ao fato da possibilidade de haver, entre pesquisa básica e aplicada, ou até mesmo no que tange à licenciatura, retornos positivos (feedbacks) entre essas atividades, fazendo com que ocorram, efetivamente, alterações relativas nos esforços empreendidos pelos pesquisadores, conforme será apontado mais à frente na seção de revisão da literatura. Outra menção digna de nota diz respeito propriamente à "vocação" à ciência básica ou aplicada das diversas áreas científicas, que tornam esses argumentos mais difíceis de serem generalizados. 
posteriores trabalhos o desenvolvimento de questões relacionadas a outros aspectos qualitativos da publicação acadêmica. ${ }^{3}$

O objeto de análise refere-se especificamente à produtividade acadêmica de docentes vinculados às universidades brasileiras, sendo a análise conduzida a partir de microdados para o período de 2000 a 2008. Para isso esse trabalho contará, além dessa seção introdutória, com uma seção de revisão da literatura sobre os determinantes da produtividade acadêmica sob a ótica da interação empresa-universidade, uma terceira seção onde são apresentados os dados utilizados no trabalho, além de uma quarta seção para apresentação da metodologia econométrica, seguida pela discussão dos resultados e, posteriormente, pelas considerações finais.

\section{Interação Empresa-Universidade e Produtividade Acadêmica: Uma Breve Revisão da Literatura}

A recente discussão sobre produtividade acadêmica está contextualizada em um ambiente de crescente restrição financeira das universidades. Segundo Mowery e Sampat (2005), as universidades em países pertencentes à Organização para a Cooperação e Desenvolvimento Econômica (OCDE) têm sofrido de crescentes restrições financeiras desde os anos de 1970. Em face do lento crescimento do financiamento público as universidades, na OCDE, tem se tornado mais agressivas e "empreendedoras" na disputa por novas fontes alternativas de financiamento, buscando uma maior aproximação com a indústria como forma de expandir seus recursos para pesquisa. ${ }^{4,5}$

3 É digno de menção que os critérios puramente quantitativos devem favorecer áreas científicas mais consolidadas, em que a produção acadêmica é feita em sua maior parte na forma de artigos em revistas indexadas e de maior penetração internacional. No Brasil ganham espaço avaliações da atividade científica e do sistema de pós-graduação, baseadas em critérios quantitativos, que auxiliam na definição de distribuição de recursos e no subsequente desempenho das diversas áreas de conhecimento.

4 Velloso (2000) destaca que um fenômeno de crescentes restrições financeiras também foi observado na América Latina desde os anos de 1980, em razão das políticas de cortes de gasto público e de ajustes estruturais, o que levou as universidades latino-americanas a buscarem fontes de recursos alternativas ao Estado.

5 É importante observar que a ideia de que a interação empresa-universidade seria a solução para as restrições financeiras das universidades não encontra apoio incondicional. Brito Cruz (2000) argumenta que a favor do papel das universidades na formação de profissionais para as empresas, ao invés de agente promotor de inovações. 
Segundo Mowery e Sampat (2005) as universidades, em vários graus, combinam funções de educação e pesquisa. Pelo lado da educação destaca-se seu papel como formadora de pessoal qualificado, com sua subsequente contratação pelas empresas, gerando, assim, um movimento de difusão do conhecimento científico produzido nas universidades por meio da atuação desses profissionais nas empresas privadas. Os "produtos" econômicos da pesquisa universitária seriam a informação científica e tecnológica, equipamentos e instrumentação, capital humano qualificado, redes de capacitações científicas e tecnológicas, além de protótipos para novos produtos e processos.

Entretanto, na sua interação com as empresas, dentro do chamado sistema nacional de inovação, existem conflitos que se situam no plano das normas da pesquisa acadêmica e industrial. Essas diferenças não estariam apenas centradas na natureza básica, ou aplicada da pesquisa científica, mas muito mais fortemente relacionadas ao valor atribuído pelos pesquisadores acadêmicos do reconhecimento e da prioridade na descoberta, bem como na cultura de conduta e disseminação dos resultados da pesquisa. Brito Cruz (2000) lembra que a complementaridade entre a pesquisa e o treinamento de estudantes altera a escala temporal de conclusão do projeto, o que do ponto de vista empresarial tem importância fundamental. Também destaca o conflito existente entre a necessidade de livre debate dos resultados da pesquisa na área acadêmica e de sigilo no campo empresarial, além da motivação menos desinteressada dos pesquisadores universitários. Essas diferenças nas normas acadêmicas e empresariais de pesquisa podem levar a pesquisadores que interagem com empresas terem distorcidos seus incentivos à publicação e disseminação dos seus resultados de pesquisa.

Uma primeira questão diz respeito ao problema de segredo, segundo Florida e Cohen (1999, apud Van Looy et alii 2004), que diminui os incentivos à publicação dos resultados em razão do seu possível caráter confidencial para as empresas. Uma segunda questão seria o direcionamento das agendas de pesquisa dos pesquisadores, agora movidos por interesses financeiros. Essa possibilidade iria de encontro ao argumento de independência de pesquisa que deveria permear a pesquisa universitária, fazendo com que os acadêmicos contribuíssem livremente para a expansão da fronteira do conhecimento, movidos primordialmente pela sua curiosidade científica. Evidências relatadas por Van Looy et alii (2004) indicam que o direcionamento 
de agenda ocorre no sentido da pesquisa mais aplicada, em detrimento da pesquisa básica, sem, contudo, ser possível concluir sobre a ordem de causalidade na relação empresa-universidade sobre esse direcionamento de pesquisa.

No entanto, em termos teóricos existem diversas possibilidades de impacto do licenciamento de tecnologia por parte das universidades sobre o esforço de pesquisa e a produtividade acadêmica. Thrusby et al. (2005), em um arcabouço de análise baseado no ciclo de vida do pesquisador, demonstra que, havendo a possibilidade de licenciamento de tecnologia, o padrão de esforço tecnológico ao longo do ciclo de vida, bem como o tempo dedicado ao lazer são dependentes das possibilidades de complementaridade entre ciência aplicada e básica na geração do estoque de conhecimento. De modo similar, as predições de modelos teóricos de ciclos de vida, propostos por Diamond (1984 apud Stephan (1996)), Weiss e Lillard (1982 apud Stephan (1996)) e Levin e Stephan (1991), são de que a produção científica, juntamente com o estoque de conhecimento e prestígio dos cientistas tende a atingir um pico, declinando posteriormente ao longo do ciclo de vida, sendo que esse padrão não se altera em razão da possibilidade de licenciamento. ${ }^{6}$

Entretanto, Thursby et al. (2005) demonstram que, considerando ou não um sistema de progressão de carreira, o licenciamento de tecnologia pode elevar a razão entre o esforço em pesquisa aplicada em relação ao esforço em pesquisa básica, havendo uma corresponde redução do tempo de lazer ao longo do ciclo de vida do pesquisador. As implicações sobre a produtividade acadêmica dependem, por conseguinte, da possibilidade do esforço em pesquisa aplicada contribuir, ou não, para o estoque de conhecimento. No caso em que somente a pesquisa básica adiciona ao resultado da pesquisa e ao estoque de conhecimento, o licenciamento de tecnologias, por necessitar de pesquisa aplicada, desvia o pesquisador da pesquisa básica, levando à redução, ao longo do ciclo de vida, do estoque de conhecimento.

No caso mais favorável, em que a pesquisas aplicada e básica são complementares ao produto de pesquisa e à geração de tecnologias para licenciamento, adicionando estoque de conhecimento, há como resultado geral que tanto o produto em pesquisa, como o estoque de

${ }^{6}$ Essa trajetória de produtividade se desenvolve em razão de um processo de escolha intertemporal em que os cientistas consideram os retornos financeiros, a finitude da vida produtiva do pesquisador e aptidão para ciência dos pesquisadores. 
conhecimento, crescem ao longo do ciclo de vida dos pesquisadores. Isto ocorre já que o esforço de pesquisa em termos gerais aumenta. Resultado semelhante ocorre no caso em que as pesquisas aplicada e básica deixam de ser complementares, e passam a ser substitutas. O que se altera sob essa hipótese é a razão entre o esforço de pesquisa aplicada e básica ao longo do ciclo de vida, que se eleva sob essa hipótese. Entretanto, o que decresce em todos os cenários é o tempo de lazer do pesquisador ao longo do ciclo de vida. Ou seja, o argumento de Thursby et al. (2005) é que o fator relevante na relação entre licenciamento de tecnologia (motivação financeira privada) e produtividade científica é a forma como conceber o papel da pesquisa aplicada na criação do estoque de conhecimento do pesquisador. Se for contributiva ao estoque de conhecimento do pesquisador, então, independentemente do fato de ser complementar, ou substituto, ao esforço de pesquisa básica, terá efeitos positivos sobre a produtividade científica.

Van Looy et al. (2004), em estudo sobre os docentes da Universidade Católica de Leuven, Bélgica, analisam o efeito da existência de projetos financiados pela indústria na academia. Ou seja, os pesquisadores buscam identificar se a interação com empresas altera a quantidade e a natureza dos artigos publicados. As mudanças no número de artigos podem ser decorrentes da proteção do conteúdo desenvolvido em razão dos interesses comerciais.

Por outro lado, as alterações na natureza dizem respeito a mudanças na orientação tradicional do pesquisador ao desenvolvimento da ciência de base em função das aplicações, que são mais próximas de tecnologias comercializáveis. Os resultados apontam que as atividades tradicionais da universidade e suas ações empreendedoras podem coexistir, pois o envolvimento dos pesquisadores no contato com empresas coincide com acréscimo no número de artigos publicados, sem afetar a natureza das publicações. Já em Van Looy et al. (2006) avalia-se o envolvimento da produtividade acadêmica com o requerimento de patentes. Contrariando o potencial efeito negativo do envolvimento de pesquisadores acadêmicos com a comercialização de tecnologias desenvolvidas nas atividades de pesquisa, os resultados demonstram que aqueles envolvidos com a requisição de patentes são mais produtivos que seus pares, assim como não existem evidências estatísticas em favor de uma mudança na pauta de pesquisa orientada para aplicações que permitem interesses comerciais. 
Entretanto, como destacam Agrawal e Henderson (2002) em trabalho sobre os pesquisadores dos departamentos de engenharia mecânica e elétrica do MIT - Massachusetts Institute of Technology, no período de 1983-1997, a representatividade das estatísticas de patentes como indicador do impacto do conhecimento desenvolvido nas universidades sobre as firmas é bastante limitado, pois requerer patentes é atividade ainda restrita a poucos pesquisadores. As publicações de artigos acadêmicos são o canal mais importante de transmissão de informações dos resultados dos esforços de pesquisa. A pesquisa ainda destaca que patentear tecnologias não reflete impacto negativo sobre a atividade de publicar artigos.

Outras evidências de inexistência entre o trade-off e comercialização de tecnologia e produtividade acadêmica são fornecidas por Gulbrandsen e Smeby (2005), para pesquisadores acadêmicos financiados por fundos industriais na Noruega. Seus resultados indicam uma significativa relação entre os fundos empresariais e o desempenho dos pesquisadores: aqueles financiados pelos fundos reportam maior quantidade de publicações que seus pares não financiados, assim como apresentam uma maior colaboração com outros pesquisadores tanto da academia, como da indústria. Para os pesquisadores entrevistados nessa pesquisa, a interação com os fundos setoriais ainda traz sugestões de pautas de pesquisa, além de ser altamente correlacionado com a produção de patentes e produtos comerciais.

O mesmo tipo de resultado é reportado por Lowe e GonzalezBrambila (2007), que analisam a produtividade acadêmica dos "docentes empreendedores”, ou seja, professores universitários que abriram uma firma para comercializar uma tecnologia previamente desenvolvida dentro da universidade, de quinze institutos de pesquisa dos EUA. Os resultados indicaram que os docentes empreendedores são mais produtivos que seus pares não empreendedores, inclusive observam que há um aumento na produtividade acadêmica após a fundação da firma, de que acordo com a concepção de universidade empreendedora, não haveria predomínio dos efeitos negativos para a pesquisa acadêmica, ao menos na amostra analisada. Goldfarb (2008) argumenta, entretanto, que o desvio da pesquisa básica para a pesquisa aplicada, e mais especificamente, para a pesquisa aplicada que não seria passível de gerar dividendos acadêmicos não ocorre de modo irrestrito para todos os cientistas. 
Segundo seu argumento, apenas os cientistas menos habilidosos, com menor capacidade de obtenção de fundos públicos de pesquisa seriam aqueles mais propensos a desviar seu foco para a pesquisa aplicada, gerando um trade-off entre pesquisa aplicada e produtividade acadêmica. Em seu estudo, em que analisa a produtividade de pesquisadores financiados pela NASA, os resultados sugerem que quando acadêmicos de alto nível permanecem por mais de um contrato atrelados à pesquisa da agência haveria um decréscimo da produtividade em pesquisa acadêmica desses pesquisadores. Isto, contudo, não ocorre no caso de pesquisadores de nível intermediário, experimentando inclusive um aumento em sua produtividade.

\section{Fonte de Dados e Análise Descritiva}

Para realizar a análise foram reunidas informações de características pessoais e das atividades realizadas por pesquisadores com vínculo de trabalho em instituições de ensino superior no Brasil no período de 2000 a 2008. Estes dados foram extraídos da Plataforma Lattes do $\mathrm{CNPq}$, que possui as características curriculares dos docentes, tais como universidade e departamento de vínculo, data de nascimento, local e ano de titulação de doutorado, sexo e o número de artigos publicados em revistas nacionais e internacionais. Essas informações foram combinadas com a base de financiamento dos Fundos Setoriais fornecida pelo MCTI, de onde foi possível identificar os pesquisadores que realizaram projetos de pesquisa com a utilização de recursos de cada fundo setorial, assim como identificar a validade do contrato.

A base de dados em questão abrange pesquisadores nascidos entre 1940 e 1980. O corte em 1940 é aplicado para maximizar a chance de que o pesquisador encontre-se em atividade na academia, enquanto que o limite em 1980 busca garantir um tempo mínimo de estudos necessário para obtenção do título de doutorado. Ademais, para evitar efeito de outliers a amostra foi restrita ao $98^{\circ}$ percentil da distribuição para o número de artigos publicados em cada grande área do conhecimento. ${ }^{7}$

7 Como será apresentado posteriormente, entre as grandes áreas do conhecimento há variabilidade do número de artigos publicados, sendo que o corte foi realizado separadamente com relação à área de atuação do pesquisador. 
Outro fator de restrição na amostra foi a eliminação de pesquisadores que haviam conseguido títulos de doutor após a obtenção de financiamento pelo fundo setorial.

Dado o objetivo do estudo de avaliar o impacto da interação dos pesquisadores com projetos de pesquisa, cuja orientação é para produtos e processos comerciais, serão considerados pesquisadores financiados pelos FS os cientistas que apresentarem contrato de pesquisa com algum FS, exceto os que receberam financiamento unicamente pelo CT-Infraestrutura. Esse fundo, diferentemente dos demais, foi criado para modernizar e ampliar a infraestrutura dos serviços de apoio à pesquisa em instituições públicas de ensino superior e, portanto, sua avaliação é realizada de modo distinto, conforme exposto na próxima seção.

Conforme informa a literatura empírica sobre o tema, a variável dependente de produção acadêmica tem como característica usual a sobredispersão, expressa na forma da lei de Lotka. ${ }^{8}$ Essa sobredispersão pode estar relacionada às heterogeneidades individuais, e no presente caso ser agravada pelo conjunto extremamente heterogêneo de pesquisadores. Um segundo fato a ser considerado no exercício de avaliação do impacto dos FS sobre a produtividade acadêmica dos pesquisadores é a possibilidade de resposta heterogênea por parte de pesquisadores em razão de pertencerem a diferentes centros universitários, além de distintas condições iniciais de formação. Isto também poderia levar a uma análise inconsistente, dada a restrição de constância dos coeficientes do modelo. ${ }^{9}$

A fim de restringir essa característica dos dados, que pode levar a um potencial problema de heterocedasticidade e/ou inconsistência do estimador, foi realizada uma estratégia de pareamento baseado em condições iniciais e de atuação científica, buscando-se homogeneizar a distribuição empírica dos pesquisadores financiados e não financiados pelos FS. Denominando o grupo de pesquisadores financiados como grupo de tratamento e o grupo de pesquisadores

8 Lotka (1926), observando a extrema desigualdade na produtividade científica dos pesquisadores, o levou a estabelecer uma relação entre a probabilidade do número de pesquisadores e o número de publicações. Essa função apresenta uma forte assimetria para a direita e indica que a freqüência relativa de autores com "X" publicações declina a taxas crescentes à medida que aumenta X. A partir dessa relação se observa que a maioria dos artigos em uma área de pesquisa usualmente são realizados por um número bastante restrito de pesquisadores.

9 Esse problema é mencionado por Angrist e Krueger (1999) quando considera a possibilidade de heterogeneidade e não linearidade nas respostas. 
não financiados como grupo de controle foi aplicado um pareamento (Matching) dos indivíduos, que permite a comparação apenas de indivíduos com características iniciais similares, aumentando, consequentemente, a precisão das estimativas e reduzindo o potencial viés proveniente da autosseleção dos indivíduos.

O procedimento de pareamento foi realizado por meio de técnicas de escore de propensão (Propensity Score), por meio de algoritmo de Nearest Neighbor para um (1) vizinho, com caliper de 0,0005 e sem reposição. Em razão da maior parte dos Fundos Setoriais ter sido criada após 2002 e a estratégia de financiamento ter tomado forte impulso somente a partir de 2003, o ano de 2002 foi tomado com ano base para a estimação do modelo probabilístico, sendo para isso eliminados da base de dados os pesquisadores financiados pelos FS nos anos de 2000 e 2001. Também para evitar problemas de comparabilidade entre os pesquisadores foi delimitada a aplicação do procedimento a apenas um conjunto de instituições de ensino superior, as quais representam o local de vínculo de trabalho de $90 \%$ dos pesquisadores financiados pelos FS. Os resultados da estimação do modelo probabilístico, bem como o teste de balanceamento, estão apresentados em apêndice.

Assim, a partir de um acesso inicial a informações de 58.896 pesquisadores, dos quais 9.588 receberam financiamento dos FS em pelo menos um ano do período delimitado, o pareamento permitiu a constituição de uma amostra composta por 11.416 pesquisadores, sendo 5.708 integrantes do grupo de tratamento e 5.708 do grupo de controle. Nessa amostra estão apenas pesquisadores com a mesma probabilidade de obtenção do financiamento em algum ano entre 2002 e 2008. Conforme pode ser observado no Gráfico 1, a densidade estimada para o escore de propensão para os dois grupos de pesquisadores, de controle $(F S=0)$ e tratamento $(F S=1)$ são idênticas entre si, o que denota que para cada pesquisador que recebeu financiamento no período entre 2002 e 2008 teve associado a ele um par para controle com probabilidade similar de receber financiamento, não tendo porém recebido o mesmo. Isto é, para cada pesquisador financiado foi um construído um contrafactual correspondente. $\mathrm{O}$ pareamento de pesquisadores foi realizado de modo a atender a condição de tendência comum na produção total de artigos, conforme também pode ser observado no Gráfico 2. 

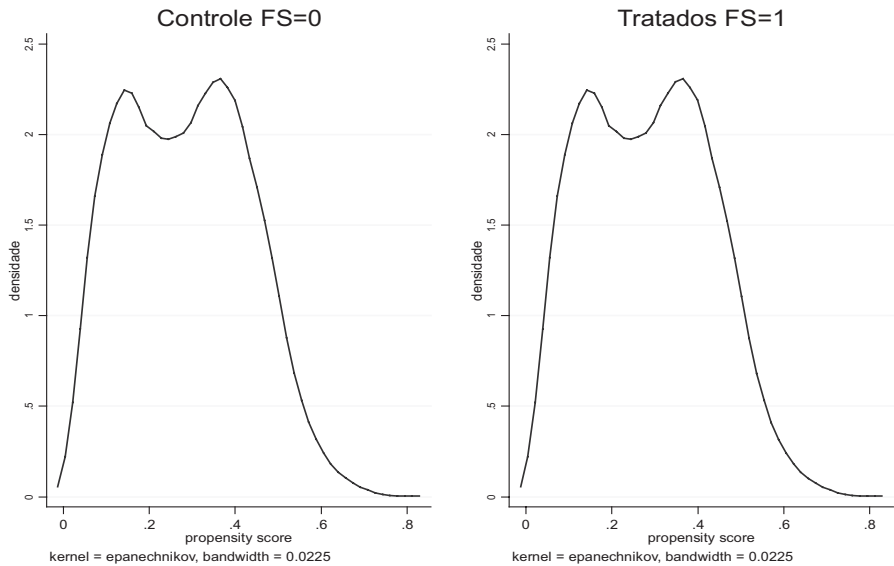

Gráfico 1 - Densidade do escore de propensão - grupos de tratamento e controle

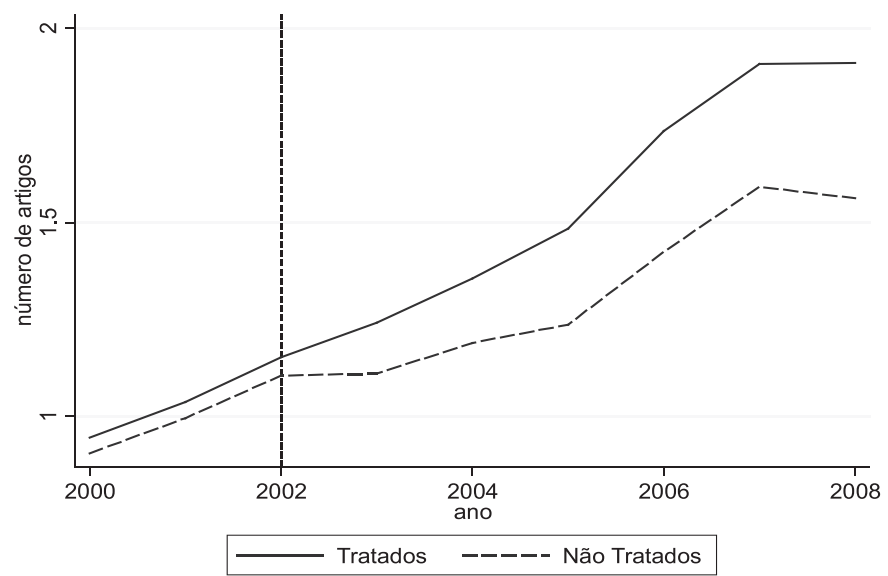

Gráfico 2 - Trajetória de média de publicação de artigos para pesquisadores dos grupos de tratamento e controle, 2000-2008

$\mathrm{Na}$ amostra constituída os pesquisadores financiados são na maioria homens $(61,42 \%)$ e estão distribuídos pelas regiões geográficas brasileiras da seguinte forma: 47,51\% no Sudeste, 17,61\% no Sul, $22,76 \%$ no Nordeste, 7,03\% no Centro-Oeste e 5,03\% no Norte do país. Os pesquisadores não financiados também são em sua maioria homens $(61,38 \%)$ e distribuídos regionalmente com $49,3 \%$ na região 
Sudeste, $18,1 \%$ na região Sul, $20,6 \%$ na região Nordeste, $7,1 \%$ da região Centro-Oeste e 4,9\% na região Norte do país.

Com relação à categorização por grandes áreas do conhecimento da CAPES é possível observar no Gráfico 4 o resultado do pareamento sobre a distribuição dos pesquisadores segundo as grandes áreas do conhecimento. A área de Exatas é aquela com maior proporção de pesquisadores com $26 \%$ nos grupos de controle e tratamento, seguido pela área de Ciências Biológicas, com aproximadamente $21 \%$ dos pesquisadores em ambos os grupos. A terceira área mais numerosa em pesquisadores é a de Ciências da Saúde com 12\% e 13\% aproximadamente de pesquisadores nos grupos de controle e tratamento, respectivamente, seguida pela área de Engenharias com aproximadamente $12 \%$ nos dois grupos. As áreas restantes detém aproximadamente $28 \%$ dos demais pesquisadores na amostra.

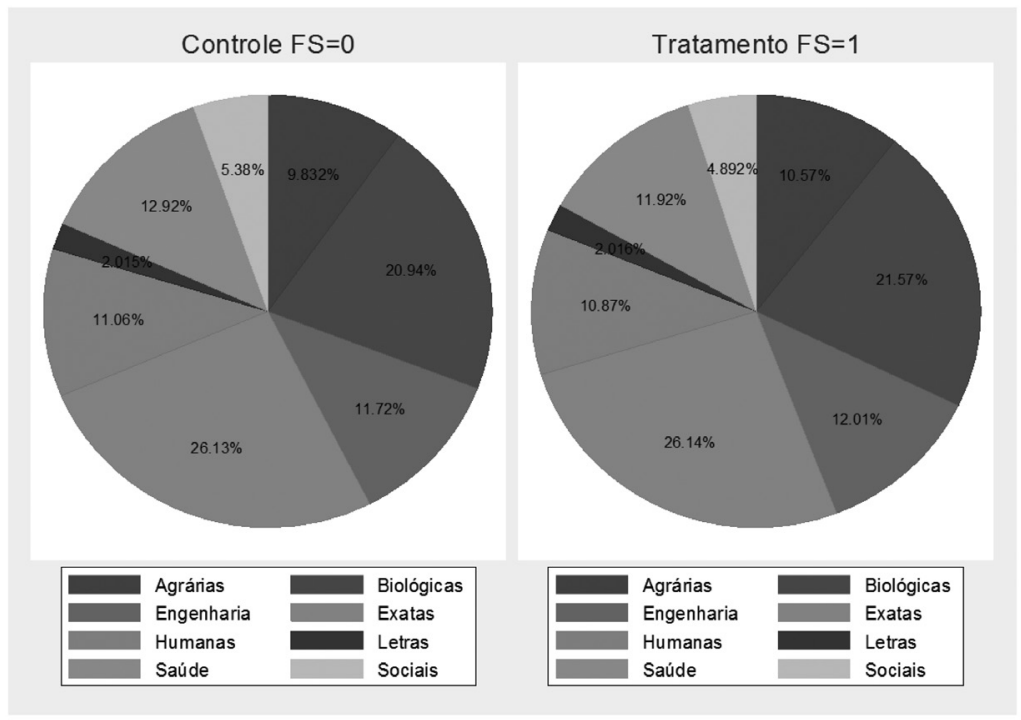

Gráfico 3 - Pesquisadores da amostra após aplicação do Matching por grandes áreas do conhecimento, 2000-2008

O estágio do ciclo de vida do pesquisador é representado pela idade do pesquisador, medida a partir da data de nascimento. Os pesquisadores que interagem com os Fundos Setoriais apresentaram data de nascimento em média no ano 1960 (com desvio padrão de 8,49 
anos), ${ }^{10}$ e mediana para o ano de nascimento de 1961. Para os pesquisadores do grupo de comparação as estatísticas de média e mediana são iguais. A única diferença em termos de momentos amostrais situa-se no coeficiente de assimetria das distribuições, com uma assimetria ligeiramente mais à esquerda para a distribuição do grupo de tratamento em relação à distribuição do grupo de controle.

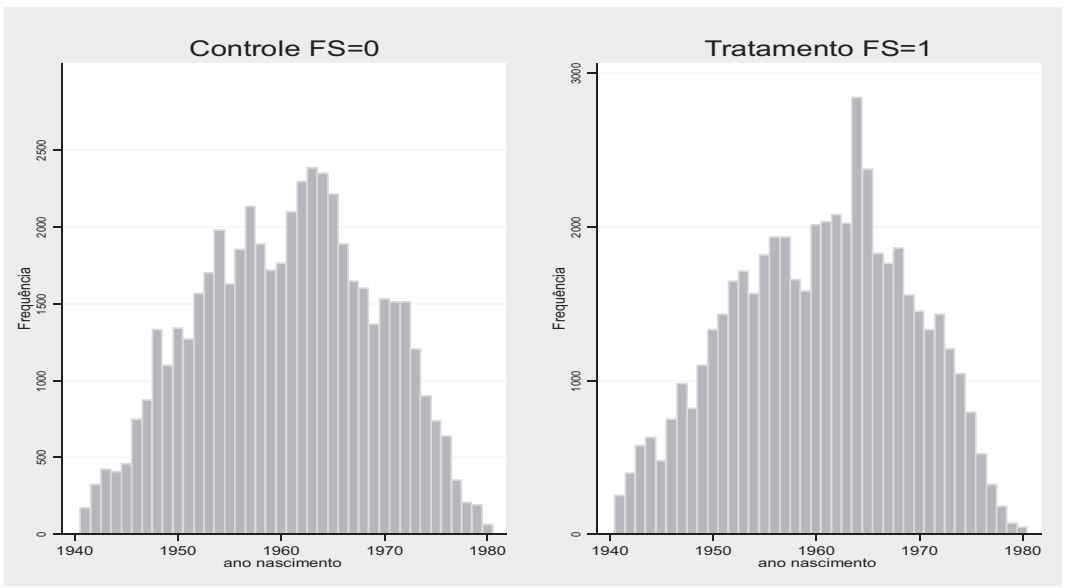

Gráfico 4 - Estatísticas do estágio do ciclo de vida dos pesquisadores após a aplicação do pareamento

Já o Gráfico 5 apresenta a distribuição empírica da frequência média de publicações de artigos para os grupos de controle e tratamento. O número de artigos publicados, utilizado aqui como índice de produtividade acadêmica, revelam em termos não condicionais que os pesquisadores que recebem financiamento dos FS são mais produtivos que seus pares do grupo de comparação. A média anual de artigos publicados, também apresentada na Tabela 1, pelo grupo de tratamento é de 1,418; enquanto pelo grupo de controle é de apenas 1,235 no mesmo período.

Da distribuição empírica do número de artigos publicados é possível identificar que a probabilidade de encontrar um pesquisador que não publicou nenhum artigo científico em determinado ano é de $41,47 \%$ para o grupo de controle e de $38,09 \%$ para o grupo de tratamento. Assim, como destacado por Lotka (1926), é possível afirmar no pre-

10 Ou seja, considerando o ano de 2008 o pesquisador médio teria 48 anos de idade. 
sente caso que as contribuições para a ciência são provenientes das atividades de um restrito grupo de pesquisadores.

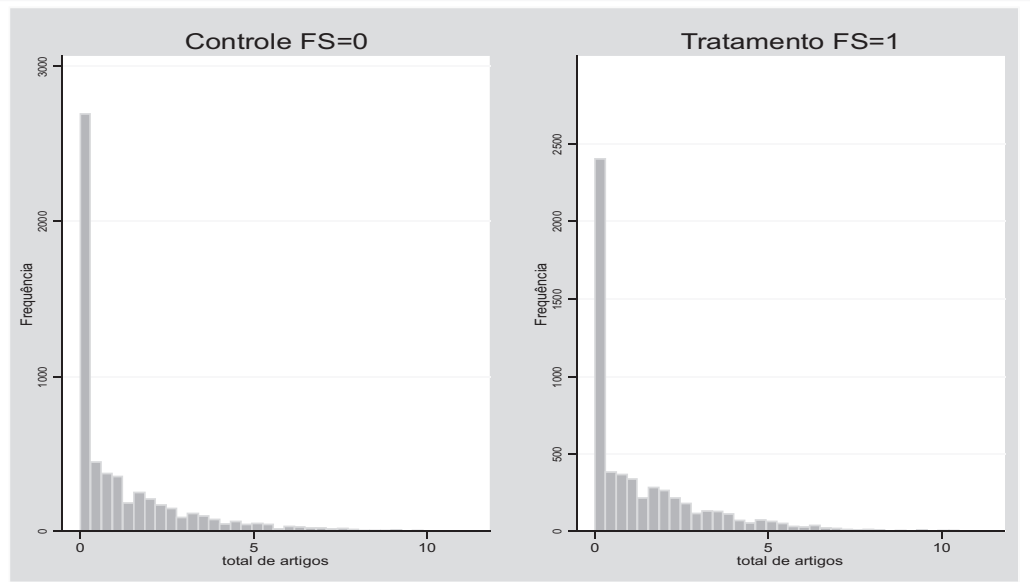

Gráfico 5 - Distribuição empírica da frequência da média de publicações de artigos para os grupos de controle e tratamento após o pareamento, 2000-2008.

Por fim, a Tabela 1 apresenta as médias anuais não condicionais de artigos publicados para os pesquisadores dos grupos de controle e tratamento. Inicialmente é interessante destacar que todas as diferenças de médias são favoráveis aos pesquisadores do grupo de tratamento, exceto para Ciências Saúde, indicando sua maior produtividade em pesquisa. ${ }^{11}$ Quando se observam as estatísticas dos pesquisadores do grupo de tratamento, percebe-se que as grandes áreas do conhecimento Ciências Agrárias e Ciências Saúde apresentam as maiores médias de artigos publicados por ano, respectivamente iguais a 2,01 e a 2,14 artigos por ano, e o grupo de controle com 1,83 e 2,27 artigos por ano, respectivamente. A categorização por gerações de pesquisadores destaca o efeito cumulativo do conhecimento, evidenciado na maior produtividade dos pesquisadores mais experientes em relação aos menos experientes na academia. ${ }^{12}$ Por fim, a divisão

${ }^{11}$ De acordo com os testes convencionais $t$ de diferenças de médias, as diferenças não seriam significantes a 1\% na produção na geração 1 e 5 e nas áreas Agrárias, Exatas, Saúde e Letras. Contudo, a elevada concentração de zeros não permite assegurar tal conclusão.

${ }^{12}$ A fim de considerar o diferencial de produtividade por geração do pesquisador foram estabelecidas, a partir da distribuição empírica da idade de nascimento, cinco gerações de pesquisadores. São elas: Geração 1: Ano nascimento < = 1949; Geração 2: $1950<=$ ano de nascimento <=1959; Geração 3: $1960<=$ ano de nascimento <= 1969; Geração 4: 1970 
entre os sexos demonstra que para ambos os sexos os pesquisadores financiados são mais produtivos, havendo na amostra uma ligeira superioridade em produtividade pesquisadores do sexo masculino.

Tabela 1 - Média anual de artigos científicos publicados entre 2000-2008

\begin{tabular}{lccc}
\hline & Não Financiados & Financiados & Diferença \\
\hline Total de Artigos & 1.235 & 1.418 & 0.184 \\
Agrárias & 1.825 & 2.008 & 0.183 \\
Biológicas & 1.381 & 1.683 & 0.301 \\
Exatas & 1.017 & 1.262 & 0.245 \\
Humanas & 0.787 & 0.976 & 0.189 \\
Sociais & 0.790 & 0.873 & 0.083 \\
Saúde & 2.272 & 2.144 & -0.129 \\
Engenharias & 0.553 & 0.797 & 0.243 \\
Letras & 0.615 & 0.673 & 0.058 \\
Geração 1 & 2.078 & 2.244 & 0.165 \\
Geração 2 & 1.564 & 1.821 & 0.257 \\
Geração 3 & 1.074 & 1.214 & 0.140 \\
Geração 4 & 0.402 & 0.533 & 0.130 \\
Geração 5 & 0.222 & 0.000 & 0.016 \\
Homem & 1.247 & 1.437 & 0.190 \\
Mulher & 1.216 & 1.390 & 0.173 \\
\hline
\end{tabular}

Uma observação relevante de ser feita sobre essas estatísticas descritivas é que, a despeito de se tratar de um grupo selecionado de pesquisadores universitários no Brasil, é possível perceber os diferenciais de produtividade por meio da comparação das médias de publicação das áreas de conhecimento. Notadamente, áreas como Ciências Agrárias, Biológicas e Saúde apresentam diferenciais de produtividade positivos em relação às áreas de Ciências Sociais Aplicadas, Ciências Humanas, ou ainda Letras e Engenharias.

Esse diferencial de produtividade está em acordo com informações divulgadas pelo Ministério da Ciência, Tecnologia e Inovação (MCTI), baseado nos dados do Institute for Scientific Information (ISI). Segundo o MCTI, a distribuição da produção científica brasileira tem expressiva concentração na grande área de Ciências Agrárias, com uma média de participação internacional de 6,8\% na média dos anos de 2007 e 2008, seguido das Ciências dos Animais e Plantas, com participação média no mesmo período de 5,6\% e Farmacologia com média de participação de 3,3\%. A grande área de conhecimen-

$<=$ ano de nascimento <= 1979; Geração 5: ano de nascimento $>=1980$.

Estud. Econ., São Paulo, vol. 43, n.4, p. 647-685, out.-dez. 2013 
to de Ciências Sociais tem participação de 2\% no total de publicações internacionais, enquanto que a área de Economia e Negócios tem participação de apenas $0,6 \%$ na média do período. A participação das áreas de Química foi de 1,85\%, sendo 1,48\% da área de Geociências e 1,5\% na área de Engenharias.

Com relação à evolução recente da produção científica nacional, é interessante observar que também, segundo informações divulgadas pelo MCTI, dos dados do ISI, que a participação brasileira na produção científica mundial é crescente ao longo dos últimos 27 anos. As publicações científicas brasileiras passaram de um total de 1.884 artigos científicos publicados em 1981 para um total de 30.415 artigos publicados no ano de 2008 . Ou seja, a pesquisa científica apresentou um crescimento exponencial no período, com um incremento anual a uma taxa média de $6,25 \%$, atingindo, no ano de 2008, 2,63\% da publicação científica mundial. É importante observar que essa evolução está fortemente relacionada à crescente participação da produção de pós-graduação, estimulada pelos critérios de avaliação da Fundação Coordenação de Aperfeiçoamento de Pessoal de Nível Superior (CAPES). Isto levou a uma mudança no comportamento dos pesquisadores, que passaram a estimular no âmbito da pós-graduação a publicação em revistas indexadas e com alto índice de impacto. Isto não pode ser observado claramente na amostra utilizada, já que o período analisado apenas se restringe apenas à década de 2000. Por outro lado, também não é possível observar esse efeito por meio dos dados geracionais, dado que o efeito do ciclo de vida sobre os dados de produtividade dos pesquisadores não permite comparações adequadas dentro da mesma geração.

O Gráfico 6 apresenta a trajetória da média de publicação dos pesquisadores financiados (tratamento) e não financiados (controle) pelos FS para as oito grandes áreas de conhecimento: Ciências Agrárias, Biológicas, Exatas e da Terra, Humanas, Sociais Aplicadas, da Saúde, Engenharias e Linguística, Letras e Artes.

O condicionamento pela grande área do conhecimento auxilia na comparação dos pesquisadores dada a as diferentes dinâmicas de publicação entre as ciências, já que existem fatores como taxas de aceitação de artigos e número de jornais disponíveis que variam em cada segmento e podem influenciar o número de artigos publicados pelos pesquisadores. 

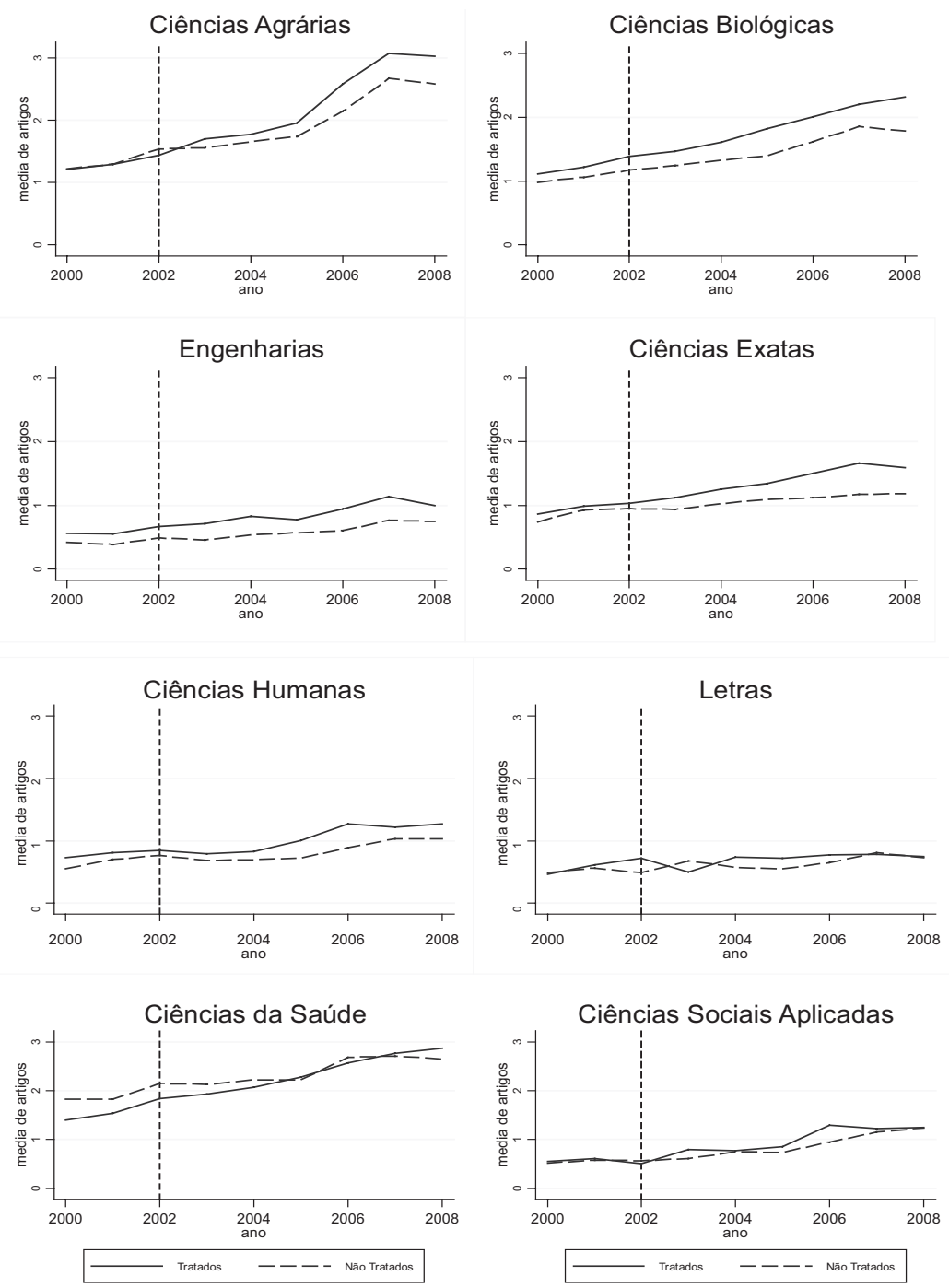

Gráfico 6 - Trajetória de média de publicação de artigos para pesquisadores dos grupos de tratamento e controle por grande área do conhecimento, 2000-2008

Como é possível observar nesse gráfico, em concordância com o Gráfico 2, para o agregado dos pesquisadores existe uma diferença no nível de publicação médio a favor dos pesquisadores financiados, principalmente para as áreas de Ciências Biológicas, Engenharias, Exatas e Humanas nos anos de 2000 e 2001. No entanto, não são em todas as áreas que esse diferencial tende a permanecer, como é 
o exemplo das áreas de Letras, ao passo que em áreas como Ciências Biológicas, Agrárias, Engenharias, Exatas, Saúdes e Humanas existe um distanciamento da produtividade dos pesquisadores em favor dos pesquisadores financiados que se amplia com o passar dos anos. Identificar se existe algum tipo de impacto da atuação dos FS sobre a produtividade docente é o objetivo do trabalho e será realizado por meio da estimação da média condicional da produtividade acadêmica, conforme apresentado na seção seguinte.

\section{Modelo Econométrico}

No modelo empírico a função que representa a produtividade dos pesquisadores nas universidades brasileiras, em que i identifica o indivíduo e t o tempo, é dada por: $Y_{i t}=F\left(X_{i t}, Z_{i}, \alpha_{i}, u_{i t}\right)$

com:

$\mathrm{Y}_{i t}$ : é o número de artigos publicados pelo indivíduo i no ano t;

$\mathrm{X}_{i t}$ : características observáveis dos pesquisadores variantes no tempo;

$\mathrm{Z}_{i}$ : características observáveis dos pesquisadores invariantes no tempo;

$\alpha_{i}$ : heterogeneidades individuais não observáveis e invariantes no tempo;

$\mathrm{u}_{i t}$ : efeito não observado variante entre indivíduos e no tempo.

De acordo a literatura teórica é possível considerar a presença de uma heterogeneidade individual não observável, como, por exemplo, fatores psicológicos, hábitos de trabalho, a habilidade inata do cientista e/ou sua motivação em produzir criativamente, capazes de explicar o desempenho produtivo do cientista. Assim, a estratégia de identificação complementar utilizada aqui será a estimação por efeitos fixos, a fim de controlar para esses efeitos não observados, além de características invariantes no tempo. Considerando que a variável dependente é o número de artigos publicados pelo pesquisador é apropriado para sua modelagem uma especificação segundo 
um modelo de contagem com dados em painel. ${ }^{13}$ Levando em conta também a evidência de sobredispersão, uma função de densidade adequada para sua especificação é a distribuição binomial negativa, de modo que o modelo proposto será representado por:

$$
\begin{gathered}
E\left(y_{i t} \mid X_{i t}, Z_{i}, c_{i}\right)=\mu=\exp \left(c+\gamma Z_{i}+\beta X_{i t}+c_{i}\right) \\
\operatorname{Var}\left(y_{i t} \mid X_{i t}, Z_{i,}, c_{i}\right)=\mu(1+\alpha \mu) \\
y_{i t}>\text { binomial negativa }
\end{gathered}
$$

Para os modelos não lineares de contagem estimados por efeitos fixos as observações de indivíduos sem publicação no período, $\sum_{t} Y_{i t}=0$, não contribuem para a derivação das condições de primeira ordem, de modo que são desprezadas na estimação.

Também é possível utilizar uma representação semi-log linear para esse modelo, por meio da transformação monotônica da média condicional acima, cujo resultado é expresso por:

$$
E\left[\ln \left(y_{i t}\right) \mid X_{i t}, Z_{i,}, c_{i}\right]=\mu+\gamma Z_{i}+\beta X_{i t}+c_{i}
$$

Conforme verificado anteriormente, em média, a frequência de zeros na publicação total de artigos por ano é de 39\%. Esse é um problema de censura na variável dependente, cuja terminologia aplicada por Wooldridge (2002) seria a de uma variável resultante de uma solução de canto. Esse fato poderia ser supostamente resultante da desutilidade, $D_{i t}^{p}$, na produção de artigos, não observada pelo pesquisador. Suponha que o pesquisador somente invista na publicação de artigos caso o retorno para essa atividade produza uma utilidade de publicação, $U_{i t}^{p}$, superior à desutilidade de destinação do seu tempo para a produção de artigo, $U_{i t}^{p}>D_{i t}^{p}$.

Se esse fosse o caso, então o modelo empírico poderia ser expresso como:

$$
\log \left(\text { Public }_{i t}\right)=\left\{\begin{array}{lc}
\mu+\gamma Z_{i}+\beta X_{i t}+c_{i}+u_{i t} & \text { s e } U_{i t}^{p}>D_{i t}^{p} \\
0 & \text { caso contrário }
\end{array}\right.
$$

\footnotetext{
${ }^{13}$ Segundo Cameron e Trivedi (2005) algumas características são importantes para definir essa preferência, como: i) alta proporção de zeros; ii) distribuição com forte assimetria à direita e iii) heterocedasticidade intrínseca, com variância crescendo com o aumento da média.
} 
Na medida em que a variável dependente não varia com os regressores quando a mesma é censurada, as estimativas do modelo linear por Mínimos Quadrados Ordinários serão inconsistentes, usualmente, viesando para baixo a magnitude dos coeficientes de inclinação. A validade do método de maximização da função de verossimilhança depende da especificação correta da distribuição dos erros, o que é problemático no modelo com dados censurados. Além disso, os estimadores com dados em painel censurados com efeitos fixos por maximização da função de verossimilhança incorrem em estimativas inconsistentes mesmo que a distribuição condicional dos erros seja corretamente especificada (Honoré, 1992). Honoré (1992) propõe a adoção de um estimador semiparamétrico denominado Mínimos Quadrados Aparados (Trimmed Least Squares - Trimmed LS) para a estimação de modelo Tobit com efeitos fixos. Esse estimador permite que os erros não sejam homocedásticos entre os indivíduos, embora necessite que sua distribuição condicional a $\left(c_{i}, X_{i s}, X_{i t}\right)$, em que s e $t$ são diferentes instantes de tempo, seja independente e identicamente distribuída para um mesmo indivíduo. Sob tal suposição demonstra-se que o estimador é consistente e assintoticamente normalmente distribuído. ${ }^{14}$

\section{No presente estudo o vetor $\mathrm{X}_{i t}$ é composto por:}

- variável dummy para financiamento dos fundos setoriais, denotada por " $F S$ ", sendo 1 para pesquisadores financiados no período determinado em contrato;

- variável dummy que relaciona se o pesquisador qualquer é pertencente a um departamento que recebeu recursos provenientes do CT-Infraestrutura a partir do ano posterior de recebimento do recurso, denotada por "Infra"; (A variável representa se o pesquisador, no ano $t$, pertence a um departamento que recebeu recursos do CT-Infraestrutura em $t-1) ;^{15}$

${ }^{14}$ Este estimador segue a proposta de Powell (1986) do estimador de mínimos desvios absolutos para dados censurados. A concepção do estimador baseia-se na ideia de tornar simétrica a distribuição condicional da variável dependente a partir de uma recensura dos dados e estimação posterior dos parâmetros por Mínimos Quadrados Ordinários. O estimador de Honoré (1992) pode ser pensado como uma generalização do estimador de Powell (1986) para um modelo Tobit com efeitos fixos. Mais detalhes sobre esse estimador podem ser vistos em Honoré (2002).

${ }^{15}$ A variável CT-Infraestrutura foi construída de modo a representar os departamentos que receberam recursos do fundo. Inicialmente foram identificados os pesquisadores que receberam apoio do fundo (e a vigência do contrato), como os recursos são investidos na modernização da infraestrutura seu efeito é maior do que o diretamente provocado no pesquisador financiado. Assim, todos os pesquisadores pertencentes a departamentos que possuem pesquisadores financiados pelo CT-Infra são também considerados financiados (os departa- 
- variável dummy de interação entre FS e Infra ("FS*Infra");

- variáveis que buscam captar o efeito do ciclo de vida sob a taxa de publicação de artigos, expresso pela idade do pesquisador e o seu quadrado ( "Idade" e "Idade $e^{2 "}$ );

- variável de estoque da publicação do pesquisador anterior ao período corrente, denotada por "Estoque ${ }_{t-1}$ ";

- variáveis dummies de ano correspondentes ao período de análise. $^{16}$

Para efeito de comparação, em alguns casos serão estimados modelos de efeitos aleatórios e pooled, tanto para o modelo negativo binomial, como para o modelo Tobit. Para esse conjunto de modelos de comparação o vetor de $Z_{\mathrm{i}}$, com variáveis invariantes no tempo, é composto por variáveis representativas do sexo, área de pesquisa, geração, região da instituição, e variáveis dummies para as universidades USP, UNICAMP e UFRJ. A próxima seção descreve os resultados obtidos com a aplicação dos modelos de regressão apresentados anteriormente.

\section{Resultados}

A Tabela 2 apresenta os resultados dos modelos com efeitos fixos em que as variáveis dependentes são o número total de artigos publicados, o número de artigos publicados em periódicos nacionais e o número de artigos publicados em periódicos internacionais, além de suas correspondentes transformações logarítmicas.

Inicialmente é importante observar que, conforme esperado, em razão da truncagem da variável dependente os coeficientes estimados do modelo linear estimado por MQO com efeitos fixos são inferiores aos demais coeficientes estimados pelos modelos Tobit e binomial

mentos foram coletados da Plataforma Lattes). A dummy é construída a partir do início do financiamento e é constante até o final do período (para captar o tempo de utilização dos recursos e o efeito permanente dos materiais adquiridos com os recursos do fundo). Isto é, se o pesquisador recebeu financiamento em 2005, entre 2005 e 2008 sua dummy de CT-Infra é 1 . E para todos os pesquisadores do seu departamento também.

${ }^{16}$ As variáveis dummies de ano serão omitidas nas tabelas a fim de poupar espaço na apresentação. 
negativo, ambos também controlando para efeitos fixos. Para esses dois últimos modelos estimados, os coeficientes associados à variável de FS foram estatisticamente significantes em ao menos um nível de significância de 5\% para o total de artigos e para a publicação de artigos nacionais. Seu impacto foi positivo sobre a produção acadêmica dos pesquisadores, representando um aumento estimado entre $5 \%$ e $6,1 \%$ na média do total de artigos publicados. ${ }^{17}$ Nessas estimações ainda é possível perceber que o impacto positivo dos FS sobre a produtividade acadêmica ocorre primordialmente sobre a publicação de artigos em periódicos nacionais, elevando sua produção entre 5,1\% e 7,6\%, segundo as diferentes estimativas proporcionadas pelos diversos modelos. No caso da publicação em periódicos internacionais o impacto estimado não é estatisticamente diferente de zero para todas as estimações. Apenas no modelo negativo binomial o coeficiente estimado para a variável FS representa um aumento de $4,0 \%$ na produção, porém significativo estatisticamente em um nível de significância de $10 \%$.

O fundo de infraestrutura não deve ter produzido impacto sobre o total da produção acadêmica e no número de artigos em periódicos nacionais, dado a não significância estatística, ao menos em um nível de significância de $10 \%$, dos coeficientes associados à variável dummy. Já nos modelos para a publicação de artigos publicados em periódicos internacionais, o impacto do Fundo de Infraestrutura, demonstra-se significativo em termos estatísticos, em ao menos um nível de significância de $10 \%$, contudo com coeficientes negativos no modelo Tobit $(-0,024)$ e binomial negativo $(-0,044)$. Conforme será verificado a seguir esse resultado é fortemente influenciado por áreas de conhecimento menos intensivas em infraestrutura física de pesquisa, como as área de Ciências Humanas e Letras, por exemplo. Já os coeficientes associados à variável interada $F S^{*}$ Infra não se apresentaram estatisticamente significantes em ao menos um nível de $10 \%$ de significância.

$\mathrm{Na}$ Tabela 3 é apresentada uma sequência de modelos estimados com diferentes ordens de defasagem para a variável dummy FS a fim de testar a possibilidade de que o impacto do financiamento ocorra com alguns anos de defasagem em razão do processo de submissão e aceitação de artigos em revistas acadêmicas com pareceristas. Foram incluídas variáveis dummies com tempo corrente até a terceira de-

17 Para o modelo semi-log linear o impacto do Fundo Setorial é calculado como $100\left(e^{\beta}-1\right)$. 
fasagem, sendo estimados modelos incluindo-se todas as defasagens simultaneamente e para cada defasagem individualmente.

Muito possivelmente devido à forte autocorrelação da variável de financiamento, produzindo multicolinearidade entre as variáveis em tempo corrente e defasadas, apurou-se em diversos modelos coeficientes não significantes estatisticamente para todas as variáveis, independentemente do estimador utilizado. A segunda observação relevante foi o fato do coeficiente associado à variável dummy em tempo corrente ser aquela com maiores coeficientes em magnitude e com maior número de casos de significância estatística. Em seguida, estão os coeficientes para a variável defasada em três períodos, denotando a possibilidade de um efeito defasado do financiamento sobre o total de artigos, contudo, com coeficientes inferiores aos estimados para a variável em tempo corrente. Ou seja, aparentemente o coeficiente em tempo corrente, muito provavelmente em razão de dependência temporal na variável de financiamento, é capaz de representar o impacto dos fundos setoriais, mesmo considerando a possibilidade de um efeito defasado decorrente do processo de submissão e publicação em periódicos com pareceristas. Assim sendo, ainda que a análise possibilite a apuração de um impacto defasado do financiamento sobre a publicação acadêmica serão privilegiados na apresentação dos resultados por áreas de conhecimento os impactos em tempo corrente. ${ }^{18}$

${ }^{18}$ Foram estimados modelos para as áreas de conhecimento com a variável dummy FS defasada em três períodos, não sendo obtidos resultados contraditórios com aqueles produzidos pelos modelos com a variável dummy em tempo corrente. Assim sendo, optou-se pela omissão dos resultados devido às restrições de espaço. 


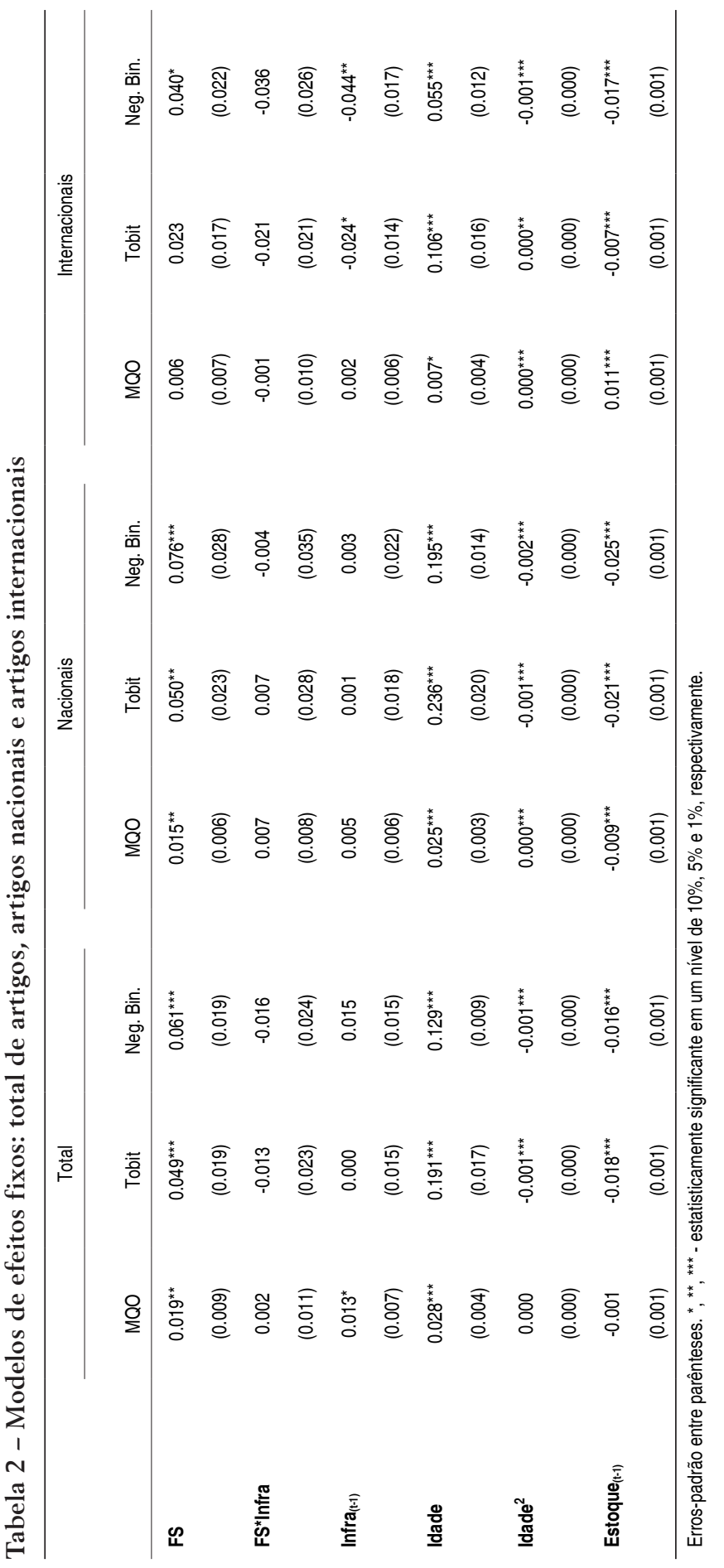




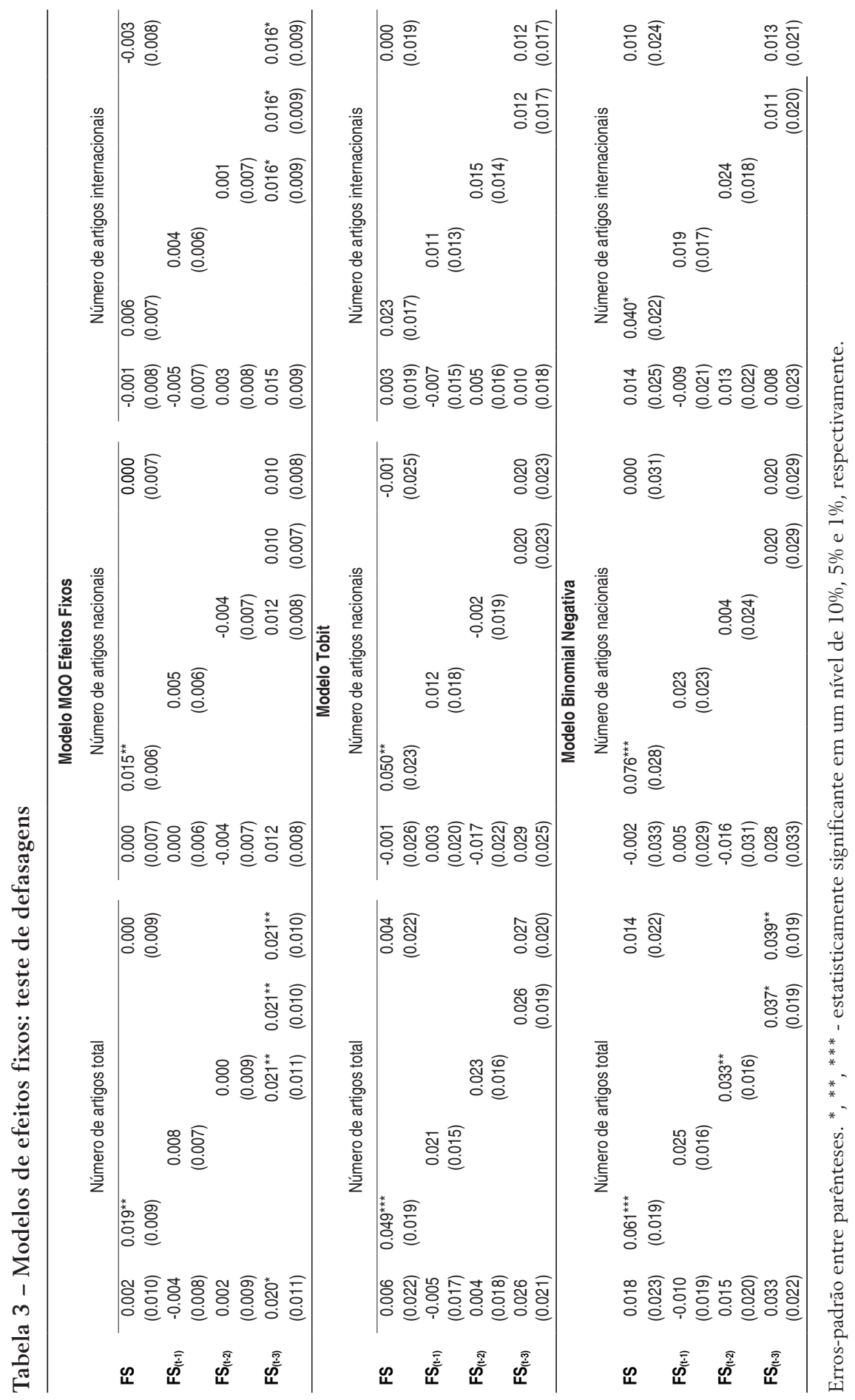


Para efeito de comparação são apresentadas na Tabela 4 as estimações de modelos por meio de estimadores pooled e de efeitos aleatórios (E.A.) dos modelos Tobit e Binomial negativo. ${ }^{19} \mathrm{O}$ objetivo dessa comparação é de auxiliar na mensuração da estratégia de identificação utilizada no trabalho. Conforme é possível observar, com exceção de apenas um modelo Tobit com efeitos aleatórios, nos demais modelos estimados os coeficientes da variável FS, além de serem estatisticamente significantes em um nível de significância de $1 \%$, também apresentam valores estimados superiores àqueles estimados pelos modelos controlados por efeitos fixos. Esse viés para cima nos coeficientes estimados deve-se à correlação da heterogeneidade não observável dos pesquisadores com o fato de ter obtido financiamento pelos Fundos Setoriais.

De fato, os pesquisadores mais produtivos tem maior probabilidade de se autosselecionarem para obter o financiamento, tendo também maior possibilidade de obtenção. Esse resultado fica mais evidente no número de publicações em artigos internacionais. Com isso é possível depreender que grande parte do diferencial produtivo no que tange à publicação em periódicos internacionais por parte dos pesquisadores financiados não se deve propriamente ao impacto dos FS, mas sim ao efeito específico não observável desses pesquisadores, que nesses modelos se confundem com o fato dos mesmos serem demandantes desse tipo de financiamento.

Tabela 4 - Resultado de regressão para modelos de comparação

\begin{tabular}{|c|c|c|c|c|}
\hline & \multicolumn{4}{|c|}{ Total de Artigos } \\
\hline & \multicolumn{2}{|c|}{ Tobit } & \multicolumn{2}{|c|}{ Binomial Negativa } \\
\hline & Pooled & E.A. & Pooled & E.A. \\
\hline \multirow[t]{2}{*}{ FS } & $0.122^{\star \star \star}$ & $0.042^{\star \star}$ & $0.125^{\star \star \star}$ & $0.069^{\star \star \star}$ \\
\hline & $(0.018)$ & $(0.018)$ & $(0.022)$ & $(0.019)$ \\
\hline \multirow[t]{2}{*}{ FS*Infra } & $-0.050^{\star \star}$ & -0.005 & $-0.066^{\star \star}$ & -0.008 \\
\hline & $(0.023)$ & $(0.022)$ & $(0.028)$ & $(0.023)$ \\
\hline \multirow[t]{2}{*}{ Infra } & $0.089^{\star \star \star}$ & $0.027^{\star}$ & $0.060^{\star \star \star}$ & $0.031^{\star \star}$ \\
\hline & $(0.014)$ & $(0.014)$ & $(0.017)$ & $(0.015)$ \\
\hline
\end{tabular}

${ }^{19}$ É importante lembrar que esses modelos incorporam parte da variação da produção entre pesquisadores que a assumem, ou que os efeitos específicos aos indivíduos estão diluídos na média produtividade dos pesquisadores (modelo pooled), ou ainda que os efeitos específicos aos indivíduos estão incorporados no termo de erro e que, por suposição, não seriam correlacionados com as demais variáveis explicativas do modelo (E.A.). 
(Continuação)

\begin{tabular}{|c|c|c|c|c|}
\hline & \multicolumn{4}{|c|}{ Artigos Nacionais } \\
\hline & \multicolumn{2}{|c|}{ Tobit } & \multicolumn{2}{|c|}{ Binomial Negativa } \\
\hline & Pooled & E.A. & Pooled & E.A. \\
\hline \multirow[t]{2}{*}{ FS } & $0.128^{\star \star \star}$ & 0.027 & $0.088^{\star \star \star}$ & $0.086^{* \star *}$ \\
\hline & $(0.018)$ & $(0.018)$ & $(0.030)$ & $(0.027)$ \\
\hline \multirow[t]{2}{*}{ FS*Infra } & $-0.054^{* *}$ & -0.015 & -0.042 & 0.003 \\
\hline & $(0.023)$ & $(0.022)$ & $(0.039)$ & $(0.034)$ \\
\hline \multirow[t]{5}{*}{$\operatorname{Infra}_{(t-1)}$} & $0.128^{\star \star \star}$ & 0.007 & $-0.092^{\star \star \star}$ & 0.002 \\
\hline & $(0.014)$ & $(0.014)$ & $(0.024)$ & $(0.021)$ \\
\hline & \multicolumn{4}{|c|}{ Artigos Internacionais } \\
\hline & \multicolumn{2}{|c|}{ Tobit } & \multicolumn{2}{|c|}{ Binomial Negativa } \\
\hline & Pooled & E.A. & Pooled & E.A. \\
\hline \multirow[t]{2}{*}{ FS } & $0.074^{* \star *}$ & $0.045^{* \star}$ & $0.168^{* \star \star}$ & $0.057^{\star \star \star}$ \\
\hline & $(0.022)$ & $(0.022)$ & $(0.024)$ & $(0.021)$ \\
\hline \multirow[t]{2}{*}{ FS*Infra } & -0.011 & 0.025 & $-0.082^{* \star *}$ & -0.035 \\
\hline & $(0.029)$ & $(0.027)$ & $(0.030)$ & $(0.025)$ \\
\hline \multirow[t]{2}{*}{$\operatorname{Infra}_{(t-1)}$} & $-0.083^{* \star *}$ & -0.008 & $0.154^{* \star \star}$ & -0.004 \\
\hline & $(0.018)$ & $(0.017)$ & $(0.018)$ & $(0.017)$ \\
\hline
\end{tabular}

Erros-padrão entre parênteses. ${ }^{*},{ }^{* *},{ }^{* * *}$ - estatisticamente significante em um nível de $10 \%, 5 \%$ e $1 \%$, respectivamente.

A Tabela 5 apresenta os resultados dos modelos Tobit e Binomial Negativa, controlando para efeitos fixos, para a variável dependente total de artigos publicados para oito grandes áreas científicas. $\mathrm{Na}$ estimação dos modelos Tobit os coeficientes estimados associados à variável de FS se apresentaram positivos significantes estatisticamente em um nível de significância de 5\% para ás áreas de Ciências da Saúde e Ciências Exatas, com respectivos impactos estimados de $10,6 \%$ e de $8,8 \%$ de acréscimo na produtividade científica. Nas estimações dos modelos de contagem os coeficientes estimados, bem como o nível de significância foram bastante próximos, com um impacto positivo de 11,5\% para as Ciências da Saúde e 8,7\% para a área de Ciências Exatas e da Terra. Para as demais áreas do conhecimento não foi apresentado significância estatística do coeficiente estimado para FS. 


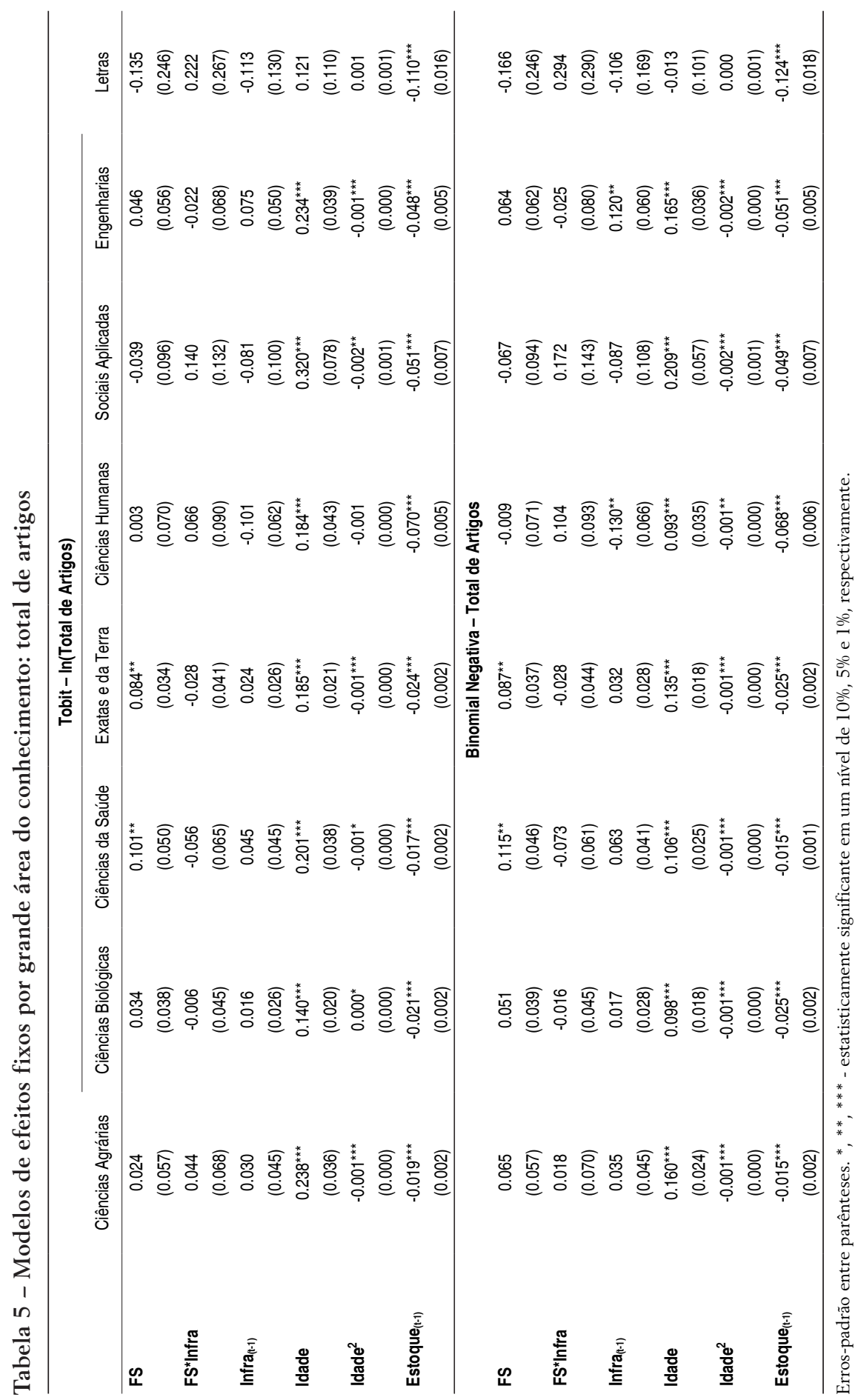




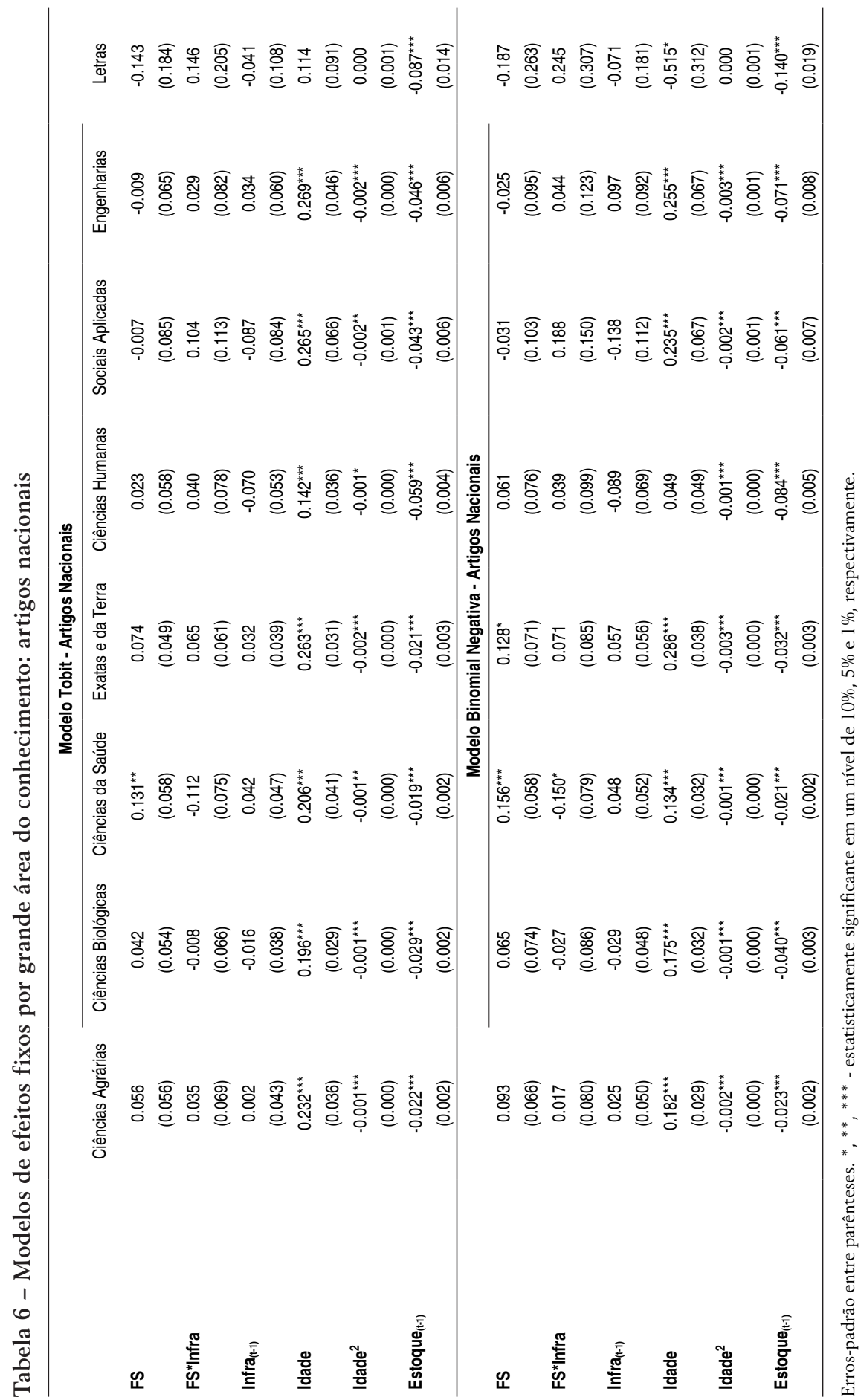




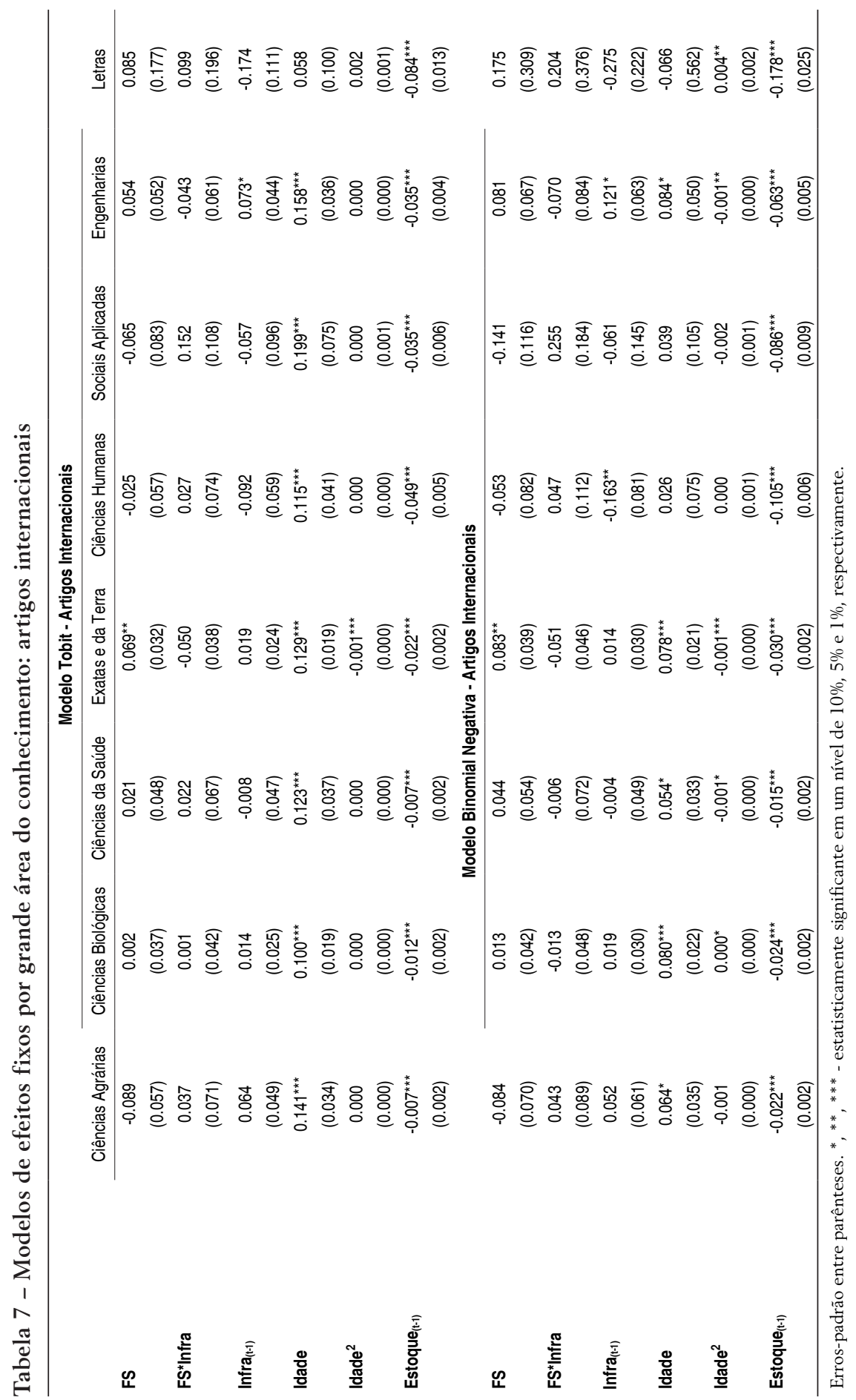


Também na Tabela 5 é possível observar que, segundo as estimações do modelo binomial negativo, o impacto do fundo de infraestrutura é negativo para as Ciências Humanas, em torno 13\%, mas é positivo em $12,1 \%$ para a área de Engenharias, ambos com coeficientes estatisticamente significativos em um nível de significância de 5\%. $\mathrm{Na}$ Já os coeficientes associados à variável interada $F S^{*}$ Infra não se apresentaram estatisticamente significantes em ao menos um nível de $10 \%$ de significância para nenhum dos modelos estimados.

Nas Tabelas 6 e 7, as estimações são discriminadas, respectivamente, segundo a publicação em periódicos nacionais e internacionais. Em consonância com os resultados para o total de artigos, as áreas científicas que apresentaram impacto positivo na publicação de artigos em periódicos nacionais foram as áreas de Ciências da Saúde e Ciências Exatas e da Terra. Porém, os impactos estimados foram superiores em magnitude, situando-se entre $14 \%$ e $15,6 \%$ para as áreas de Ciências da Saúde de acordo com o modelo estimado e de 15,6\% para as áreas de Ciências Exatas e da Terra. Com relação à publicação de artigos em periódicos internacionais merecem destaque os resultados para as áreas de Ciências Exatas e da Terra, que apresentaram um impacto positivo para os Fundos Setoriais em torno de $7,1 \%$ a $8,4 \%$ dependendo do modelo estimado e demonstrou que o impacto do fundo de infraestrutura nas áreas de Ciências Humanas (negativo) e de Engenharias (positivo) se dá primordialmente sobre artigos publicados em periódicos internacionais.

Complementando a análise do modelo econométrico, as estimativas de ciclo de vida dos pesquisadores, fornecidas pelo modelo Binomial Negativa, indicam que o pico da produção científica de um pesquisador está em torno dos 57 anos de idade, com a publicação média de 3,7 artigos em um mesmo ano, conforme ilustrado no Gráfico 9. ${ }^{20}$ Quando estimados separadamente para a publicação em periódicos nacionais e internacionais, os picos da produção ficam respectivamente em 52 e 58 anos, respectivamente. Já para as estimações apresentadas na Tabela 7, em que as estimações são conduzidas para as oito grandes áreas científicas, demonstram que em todas as áreas, exceto para a área de Ciências Biológicas, o pico do ciclo de vida dos pesquisadores nessas áreas situam-se em torno da média de 55 anos, com destaque para o pico precoce na área de Ciências Sociais

${ }^{20} \mathrm{O}$ pico da relação entre idade e produção é calculado a partir da igualdade $\beta_{3}+2 \beta_{4}$, em que $\beta_{3}$ é o coeficiente associado à variável idade e $\beta_{4}$ o coeficiente associado à variável idade ${ }^{2}$ no modelo binomial negativo. 
Aplicadas, em torno de 44 anos de idade, e um pouco mais atrasado na área de Ciências Exatas e da Terra, em torno de 61 anos de idade. Na área de Ciências Biológicas o pico ocorreria apenas em torno dos 92 anos de idade, algo extremamente fora do padrão nacional, enquanto que para a área de Linguística, Letras e Artes, em razão dos sinais e significância dos coeficientes, não foi possível estimar um pico de produtividade.

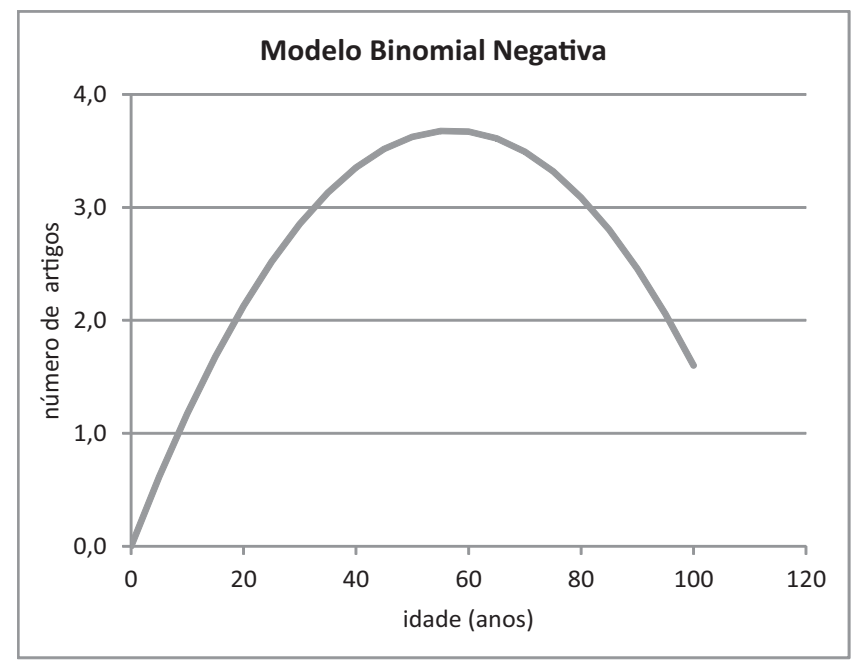

Gráfico 9 - Relação quadrática entre total de artigos publicados e a idade pesquisador

Tabela 8 - Idade de pico da produção científica para os pesquisadores das grandes áreas do conhecimento- modelo Binomial Negativa

\begin{tabular}{|c|c|}
\hline Área Científica & Idade \\
\hline Ciências Agrárias & 58.0 \\
\hline Ciências Biológicas & 92.3 \\
\hline Ciências Exatas e da Terra & 60.8 \\
\hline Ciências Humanas & 57.3 \\
\hline Ciências Sociais Aplicadas & 43.9 \\
\hline Ciências da Saúde & 54.8 \\
\hline Engenharias & 52.9 \\
\hline Lingüísticas, Letras e Artes & - \\
\hline
\end{tabular}


Já a variável Estoque de publicação, defasada em um período, contribui, em média, negativamente para publicação de novos artigos, levando a um declínio de $1,8 \%$ a $1,6 \%$ na produção total corrente de artigos segundo os modelos Tobit e Binomial Negativa, respectivamente. Contudo, esse efeito se manifesta mais fortemente na publicação de artigos em periódicos nacionais, em que o efeito alcança o valor de $2,1 \%$ a $2,5 \%$ negativos para os mesmos modelos. Já o efeito do estoque passado é menor na publicação de artigos em periódicos internacionais, em que as estimativas apresentaram coeficientes igualmente negativos de $-0.7 \%$ e $-1.7 \%$, respectivamente para os modelos Tobit e Binomial Negativa.

\section{Conclusão}

Este trabalho traduz um esforço inédito de se medir o impacto da política de fundos setoriais sobre a publicação científica por parte dos pesquisadores universitários durante o período de 2000 a 2008. Com dados extraídos da Plataforma Lattes do CNPq e da base de financiamento dos Fundos Setoriais, fornecida pelo MCT. Para condução da análise foi construída uma amostra com pesquisadores financiados e não financiados pelos fundos Setoriais, utilizada na estimação de modelos econométricos em painel, especificados segundo a teoria de ciclo de vida do pesquisador.

Os resultados, em termos gerais, apontam para um efeito positivo, porém limitado, da política de fundos setoriais sobre a publicação acadêmica dos pesquisadores universitários, não havendo, portanto, evidência da existência de um trade-off entre a interação empresa -universidade, mediada pela política de fundos setoriais, e a produtividade acadêmica dos pesquisadores. O impacto global da política de financiamento de fundos setoriais deve ter levado a um aumento entre a $5 \%$ a $6 \%$ na produção acadêmica dos pesquisadores nacionais no período considerado. No entanto, esse efeito médio está concentrado em áreas de conhecimento específicas como as Ciências da Saúde, Ciências Exatas e da Terra e Engenharias.

O incremento na publicação de artigos em periódicos nacionais se dá nas grandes áreas científicas de Ciências da Saúde e Ciências Exatas e da Terra. Esses resultados indicam que as pesquisas realizadas com 
o apoio dos FS encontram meio principal de divulgação a publicação em periódicos nacionais, tendo, portanto, impacto científico limitado. Foi observado que os fundos Setoriais não são capazes de alterar a trajetória produtiva dos pesquisadores no que tange à publicação de artigos em periódicos internacionais, estando tal resultado mais fortemente relacionado às características individuais dos pesquisadores.

Com relação ao impacto positivo do financiamento do CT-INFRA, Fundo de Infraestrutura, destinado ao financiamento para ampliação e modernização dos serviços de apoio à pesquisa desenvolvida em instituições públicas de ensino superior e de pesquisas brasileiras, este somente verificado sobre a publicação de periódicos internacionais. Mais especificamente, o impacto positivo se dá sobre a área Engenharias, possivelmente associado aos grandes investimentos promovidos pelo fundo CT-Petro.

Outro resultado complementar do trabalho, útil à compreensão da dinâmica produtiva dos pesquisadores brasileiros, é a estimação do ciclo de vida dos pesquisadores. Conforme os resultados dos modelos estimados o pico da produção científica de um pesquisador que publica em periódicos acadêmicos ocorre em torno dos 57 anos de idade, com a publicação média de 3,7 artigos em um mesmo ano. Quando discriminadas segundo as grandes áreas científicas, os resultados demonstram que, em seis das oito grandes áreas, o pico do ciclo de vida dos pesquisadores situa-se em torno da média de 55 anos de idade. Apenas para a área de Ciências Biológicas o pico ocorreria apenas em torno dos 92 anos, algo extremamente fora do padrão nacional, indicando que a abordagem de ciclo de vida não encontra apoio nessa área de conhecimento.

Obviamente, esse tipo de avaliação deverá ser aprimorada, dadas as diversas limitações que uma abordagem eminentemente quantitativa possui, podendo ser conduzida em trabalhos posteriores por meio da combinação de avaliações quantitativa e qualitativa, sobre a forma de apropriação e utilização por parte das universidades dos financiamentos fornecidos pela política de Fundos Setoriais. Entretanto, considerando a relevante contribuição financeira que atualmente representam os Fundos Setoriais à área acadêmica, é possível questionar mais profundamente a eficácia do financiamento. A despeito de uma concepção moderna do financiamento às atividades inovativas e tecnológicas do sistema produtivo, na sua operacionalização o sistema 
de fundos setoriais ainda está intrinsecamente relacionado a conceitos lineares de geração de inovação. Dito isso é importante incentivar a busca não apenas de eficiência dos recursos, mas também de eficácia dos recursos, enquanto transformadores ou direcionadores das atividades de pesquisas universitárias.

\section{Referências}

AGRAWAL, A. and HENDERSON, R. "Putting patents in context: exploring knowledge transfer from MIT” Management Science, 48, pp. 44-60. 2002.

ALLISON, P. and STEWART, J. "Productivity differences among scientists: Evidence for accumulative advantage," American Sociological Review, 39, August 1974.

ANGRIST, J. D. and KRUEGER, A. B. "Empirical strategies in labor economics" in Handbook of Labor Economics, vol. 3, Edited by O. Ashenfelter and D. Card, Elsevier Science, 1999.

BRITO CRUZ, C.H. "Universidade, a empresa e a pesquisa que o país precisa". Texto apresentado ao Grupo Temático de Ciência e Tecnologia do Fórum São Paulo Século XXI da Assembléia Legislativa do Estado de São Paulo, 2000.

CAMERON, A. C. and TRIVEDI, P. K. Microeconometrics using Stata. Stata Press, 2009.

CARAYOL, N. and MIREILLE, M.; "Does research organization influence academic production? Laboratory level evidence from a large European university" Research Policy 33, p. 1081-1102. 2004

DE NEGRI, F.; ALVES, P. F.; KUBOTA, L. C.; CAVALCANTE, L. R.; DAMASCENO, E. C.; "Perfil das empresas integradas ao sistema federal de C,T\&I e aos fundos setoriais: uma análise exploratória". Projeto Metodologia de avaliação dos fundos setoriais. Convênio MCT-Finep/IPEA/ UFMG. Relatório 2. Novembro, 2009.

DUNDAR, H.; and LEWIS D. R.; "The determinants of research productivity in higher education". Research in Higher Education. Vol 39. No 6, p.607-631. 1999.

ETZKOWITZ, H. and LEYDESDORFF, L. "The dynamics of innovation: from National Systems and 'mode 2' to a triple helix of university-industry-government relations," Research Policy, 29, p. 109-123, 2000.

FOX, M. "Publication productivity among scientists: A critical review," Social Studies of Science, 13, p. $283-305,1983$

GOLDFARB, B.; "The effect of government contracting on academic research: Does the source the funding affect scientific output? ’'Research Policy 37, p.41-58. 2008.

GONZALEZ-BRAMBILA, C.; and VELOSO, F.M.; “The determinants of Research Output and Impact: A Study of Mexican Research”. Research Policy, 36, p. 1035-51, 2007.

GULBRANDSEN, M. and SMEBY, J.C.; "Industry funding and university professors'research performance" Research Policy 34, p. 932-950. 2005.

HONORÉ, B. E. (1992) “Trimmed lad and least squares estimation for truncated and censored regression models with fixed effects", Econometrica, 60 (3), p. 533-565.

LEVIN, S. and STEPHAN, P. "Research productivity over the life cycle: Evidence for academic scientists," The American Economic Review, 81, p. 114-32, March 1991

LOTKA, A. "The frequency distribution of scientific productivity," Journal of the Washington Academy of Sciences, 16, June 1926.

Estud. Econ., São Paulo, vol. 43, n.4, p. 647-685, out.-dez. 2013 
LOWE, R. A. and GONZALES-BRAMBILA, C. "Faculty entrepreneurs and research productivity", Journal of Technology Transfer, 32, p. 173-194, 2007.

MOWERY, D. and SAMPAT, B.; "Universities in National Innovation Systems” Inf: FAGERBERG, J.; MOWERY, D. E NELSON. R. The Oxford Handbook of Innovation. Oxford: Oxford University Press. 2005.

PEREIRA, N. M.; "Fundos setoriais: avaliação das estratégias de implementação e gestão" Ipea (texto para discussão, 1.136). 2005.

PACHECO, C. A. As reformas da política nacional de Ciência, Tecnología e Inovação no Brasil (19992002), Manual de Politicas Públicas-CEPAL, 2007

STEPHAN, P. "The Economics of Science," Journal of Economic Literature, 34, p. 1199-1235, September 1996.

SUZIGAN, W. E ALBUQUERQUE, E. "A interação entre universidades e empresas em perspectiva histórica no Brasil”. Texto para Discussão número 329, Cedeplar/UFMG. 2008.

THURSBY, M., THURSBY, J. and GUPTA-MUKHERJEE, S.; "Are there real effects of licensing on academic research? A life cycle view" National Bureau of Economic Research, Working Paper 11947. 2005.

TURNER, L. and MAIRESSE, J. "Individual Productivity Differences in Public Reserch: How important are non-individual determinants? An Econometric Study of French Physicist's Publications (1986-1997)", Centre National de la Recherche Scientifique, 75 - Paris (France), 2002.

VAN LOOY, B.; RANGA, M.; CALLAERT, J. and ZIMMERMANN, E. "Combining entrepreneurial and scientific performance in academia: towards a compounded and reciprocal Matthew-effect?" Research Policy, 33, p. 425-41, 2004.

VAN LOOY, B.; CALLAERT, J; and DEBACKERE, K.; "Publication and patent behavior of academic researchers: conflicting, reinforcing or merely co-existing?" Research Policy, 35, pp 596-608, 2006.

VELOSSO, Jacques "Universidade na América Latina: Rumos do Financiamento" Cadernos de Pesquisa, 110, p. 39-66, julho/2000.

\section{Apêndice: Propensity Score Matching}

Para a definição do modelo probit para o cálculo dos escores de propensão foi utilizado o algoritmo stepwise de seleção de modelos do mais geral para o mais restrito, selecionando-se o modelo final em que as variáveis fossem significantes em ao menos um nível de significância de 20\%. Assim, sendo as variáveis utilizadas no modelo para a probabilidade de acesso aos Fundos Setoriais (FS), em 2002. Na lista de variáveis estavam presentes o $\log$ (total_artigo), $\log \left(\right.$ total_artigo $\left.^{2}\right), \log \left(\right.$ total_artigo $\left._{t-1}\right)$, experiencia, experiencia ${ }^{2}, i d a-$ de, idade ${ }^{2}$, homem, além de variáveis dummies de área de conhecimento e regionais. A estimação do modelo reduzido é apresentada na Tabela la, enquanto que na Tabela $1 \mathrm{~b}$ estão apresentados os testes de balanceamento para as covariadas do modelo. 
Tabela la - Modelos de probit para propensity score

\begin{tabular}{|c|c|c|c|c|}
\hline & Coeficientes & D.P. & $z$ & $p>|z|$ \\
\hline Log(total_artigo $(t))$ & 0.131 & 0.018 & 7.46 & 0.00 \\
\hline Log(total_artigo $\left.0_{(-1-1)}\right)$ & 0.034 & 0.007 & 5.03 & 0.00 \\
\hline Log(total_artigo $\left.{ }_{(t)}\right)^{2}$ & 0.068 & 0.010 & 6.84 & 0.00 \\
\hline experiencia & 0.045 & 0.002 & 21 & 0.00 \\
\hline experiencia $^{2}$ & -0.002 & 0.000 & -13.55 & 0.00 \\
\hline idade & 0.108 & 0.009 & 11.83 & 0.00 \\
\hline idade $^{2}$ & -0.001 & 0.000 & -11.59 & 0.00 \\
\hline homem & 0.133 & 0.017 & 7.96 & 0.00 \\
\hline artigosud & -0.054 & 0.010 & -5.24 & 0.00 \\
\hline sul & -0.361 & 0.024 & -14.82 & 0.00 \\
\hline sudeste & -0.388 & 0.021 & -18.34 & 0.00 \\
\hline sudagro & -0.100 & 0.020 & -4.95 & 0.00 \\
\hline centro-oeste & -0.258 & 0.033 & -7.85 & 0.00 \\
\hline saude & -0.655 & 0.033 & -19.87 & 0.00 \\
\hline letras & -1.032 & 0.044 & -23.53 & 0.00 \\
\hline sociais & -0.697 & 0.024 & -28.48 & 0.00 \\
\hline engenharias & 0.245 & 0.030 & 8.28 & 0.00 \\
\hline exatas & -0.642 & 0.026 & -25.12 & 0.00 \\
\hline constante & -1.870 & 0.225 & -8.32 & 0.00 \\
\hline Número de observações & & & & 36458 \\
\hline LR chi2(18) & & & & 4842.99 \\
\hline Prob. > chi2 & & & & 0.00 \\
\hline Pseudo R2 & & & & 0.1343 \\
\hline
\end{tabular}


Tabela $1 \mathrm{~b}$ - Testes de balanceamento

\begin{tabular}{|c|c|c|c|c|c|}
\hline \multirow[b]{2}{*}{ variável } & & \multicolumn{2}{|c|}{ Média } & \multicolumn{2}{|c|}{ Teste t } \\
\hline & & Tratamento & Controle & $t$ & $p>|t|$ \\
\hline \multirow{2}{*}{ homem } & Unmatched & 0.616 & 0.486 & 19.85 & 0.000 \\
\hline & Matched & 0.603 & 0.615 & -1.49 & 0.136 \\
\hline \multirow{2}{*}{ data_doutorado } & Unmatched & 1999.700 & 2002.600 & -34.27 & 0.000 \\
\hline & Matched & 2000.000 & 2000.000 & 0.47 & 0.639 \\
\hline \multirow{2}{*}{ Log(total_artigo } & Unmatched & 1.027 & 0.493 & 28.34 & 0.000 \\
\hline & Matched & 0.881 & 0.885 & -0.12 & 0.907 \\
\hline \multirow{2}{*}{ Log(total_artigo $\left.0_{(t-1)}\right)$} & Unmatched & 0.924 & 0.452 & 26.39 & 0.000 \\
\hline & Matched & 0.791 & 0.805 & -0.51 & 0.612 \\
\hline \multirow{2}{*}{ ano_nascimento } & Unmatched & 1961.100 & 1962.900 & -15.07 & 0.000 \\
\hline & Matched & 1961.300 & 1961.400 & -0.5 & 0.620 \\
\hline \multirow{2}{*}{ sul } & Unmatched & 1.179 & 1.211 & -5.97 & 0.000 \\
\hline & Matched & 1.181 & 1.187 & -0.89 & 0.371 \\
\hline \multirow{2}{*}{ sudeste } & Unmatched & 1.443 & 1.492 & -7.44 & 0.000 \\
\hline & Matched & 1.456 & 1.469 & -1.56 & 0.118 \\
\hline \multirow{2}{*}{ centro-oeste } & Unmatched & 1.073 & 1.081 & -1.99 & 0.047 \\
\hline & Matched & 1.076 & 1.073 & 0.53 & 0.597 \\
\hline \multirow{2}{*}{ Agrarias } & Unmatched & 0.107 & 0.070 & 10.71 & 0.000 \\
\hline & Matched & 0.105 & 0.096 & 1.82 & 0.069 \\
\hline \multirow{2}{*}{ Engenharia } & Unmatched & 0.132 & 0.053 & 24.17 & 0.000 \\
\hline & Matched & 0.122 & 0.121 & 0.13 & 0.894 \\
\hline \multirow{2}{*}{ Exatas } & Unmatched & 0.103 & 0.176 & -15.06 & 0.000 \\
\hline & Matched & 0.109 & 0.114 & -0.96 & 0.336 \\
\hline \multirow{2}{*}{ Letras } & Unmatched & 0.020 & 0.087 & -19.52 & 0.000 \\
\hline & Matched & 0.021 & 0.020 & 0.48 & 0.628 \\
\hline \multirow{2}{*}{ Saude } & Unmatched & 0.050 & 0.099 & -13.11 & 0.000 \\
\hline & Matched & 0.053 & 0.056 & -0.76 & 0.446 \\
\hline \multirow[t]{2}{*}{ Sociais } & Unmatched & 0.110 & 0.235 & -23.4 & 0.000 \\
\hline & Matched & 0.118 & 0.113 & 0.95 & 0.343 \\
\hline
\end{tabular}

